Elsevier Editorial System(tm) for Journal of Sound and Vibration Manuscript Draft

Manuscript Number: JSV-D-11-00129

Title: ON EXACT AND APPROXIMATED FORMULATIONS FOR SCALING MODE SHAPES IN OPERATIONAL MODAL ANALYSIS BY MASS AND STIFFNESS CHANGE

Article Type: Full Length Article

Section/Category: J Analytical methods and modelling for linear vibration and acoustics

Keywords: operational modal analysis; scaling factors; mass-change method

Corresponding Author: Mr MANUEL LOPEZ AENLLE, Ph.D.

Corresponding Author's Institution: University of Oviedo

First Author: MANUEL LOPEZ AENLLE, Ph.D.

Order of Authors: MANUEL LOPEZ AENLLE, Ph.D.; Rune Brincker, Professor; Pelayo Fernández, PhD; Alfonso Fernández-Canteli, Professor

Abstract: When operational modal analysis (OMA) is used to estimate modal parameters, mode shapes cannot be mass normalized. In the past few years, some equations have been proposed to scale mode shapes using the mass-change method, which consists of repeating modal testing after changing the mass at different points of the structure where the mode shapes are known. In this paper, the structural dynamic modification theory is used to derive a set of equations, from which all the existing formulations can be derived. It is shown that the known equations can be divided into two classes, the exact and the approximated equations, where the former class does in fact fulfill the equations derived from the theory of structural modification, whereas the remaining equations do not, mainly because the change of the mode shapes of the modified structure is not taken properly into account. The paper illustrates by simulations the large difference in accuracy that exists between the approximate and the exact formulations. The paper provides two new exact formulations for the scaling factors, one for the non-modified structure and - as the first time in the literature - one for the modified structure. The paper illustrates by simulation the influence of errors on the measured natural frequencies and mode shapes on the estimation of the scaling factors using the two exact formulations from the literature and the new exact formulation proposed in this paper. Further, the paper illustrates statistics of the errors on mode shape scaling. All simulations were carried out using a plate with closely spaced modes. 


\title{
ON EXACT AND APPROXIMATED FORMULATIONS FOR SCALING MODE SHAPES IN OPERATIONAL MODAL ANALYSIS BY MASS AND STIFFNESS CHANGE
}

\author{
M. López-Aenlle ${ }^{\mathrm{a}^{*}}$, R. Brincker ${ }^{\mathrm{b}}$, F. Pelayo ${ }^{\mathrm{a}}$, A. F. Canteli ${ }^{\mathrm{a}}$ \\ ${ }^{a}$ Department of Construction and Manufacturing Engineering, University of Oviedo, \\ Campus de Gijón, Zona Oeste, Edificio 7, 33203, Gijón, Spain. E-mail: \\ aenlle@uniovi.es \\ b Aarhus School of Engineering, Aarhus University, Dalgas Avenue 2, 8000 Aarhus C, \\ Denmark, E-mail: rub@iha.dk
}

\begin{abstract}
When operational modal analysis (OMA) is used to estimate modal parameters, mode shapes cannot be mass normalized. In the past few years, some equations have been proposed to scale mode shapes using the mass-change method, which consists of repeating modal testing after changing the mass at different points of the structure where the mode shapes are known. In this paper, the structural dynamic modification theory is used to derive a set of equations, from which all the existing formulations can be derived. It is shown that the known equations can be divided into two classes, the exact and the approximated equations, where the former class does in fact fulfill the equations derived from the theory of structural modification, whereas the remaining equations do not, mainly because the change of the mode shapes of the modified structure is not taken properly into account. The paper illustrates by simulations the large difference in accuracy that exists between the approximate and the exact formulations. The paper provides two new exact formulations for the scaling factors, one for the non-modified structure and - as the first time in the literature - one for the modified structure. The paper illustrates by simulation the influence of errors on the measured natural frequencies and mode shapes on the estimation of the scaling factors using the two exact formulations from the literature and the new exact formulation proposed in this paper. Further, the paper illustrates statistics of the errors on mode shape scaling. All simulations were carried out using a plate with closely spaced modes.
\end{abstract}

Keywords: operational modal analysis, scaling factor, mass-change method. 


\section{Nomenclature}

[ ] Matrix

\{\}$\quad$ Vector

[c] Damping matrix

[I] Identity matrix

[k] Stiffness matrix

[m] Mass matrix

$\{\mathrm{p}(\mathrm{t})\}$ Force vector

$\mathrm{Nm} \quad$ Number of modes

$\alpha_{0 \mathrm{i}} \quad$ Scaling factor of the i-th mode of the original structure

$\alpha_{\text {Ii }} \quad$ Scaling factor of the $i$-th mode of the modified structure

$[\Delta \mathrm{m}] \quad$ Mass-change matrix

$[\Delta \mathrm{k}] \quad$ Stiffness change matrix

$\left\{\phi_{0 \mathrm{i}}\right\} \quad$ Scaled i-th mode shape vector of the original structure

$\left\{\phi_{\mathrm{Ii}}\right\} \quad$ Scaled i-th mode shape vector of the modified structure

$\left\{\Psi_{0 \mathrm{i}}\right\} \quad$ Unscaled i-th mode shape vector of the original structure

$\left\{\psi_{\text {Ii }}\right\}$ Unscaled i-th mode shape vector of the modified structure

$\omega_{0 \mathrm{i}} \quad$ Natural frequency original structure of $\mathrm{i}$-th mode

$\omega_{\text {Ii }} \quad$ Natural frequency modified structure of i-th mode 


\section{Introduction}

Operational modal analysis (OMA) has been used in the last years in many civil [1, $2,3]$ and mechanical applications $[4,5]$. OMA makes use of natural or operating loads to excite a structure, which can be considered an important advantage in large structures $[6,7]$, where the use of artificial excitation devices may be expensive or impractical. Another advantage is that the modal tests can be performed with the structure in operation such as in a bridge, where the bridge traffic does not need to be interrupted during the test. Rather, the traffic loading will be used as the excitation source, so that the natural response of the bridge to that loading will be measured and used to perform an OMA identification [3]. Vehicles and mechanical systems can be tested in their inservice condition $[8,9]$.

Since the forces in OMA are unknown, the mode shapes cannot be mass normalized and only the un-scaled mode shapes can be determined for each mode $[10,11,12,13]$. However, the scaling factors of the mode shapes must be known in applications where a frequency-response matrix needs to be assembled from the modal parameters such as structural modification [14, 15], load estimation [16], health-monitoring applications [14], damage detection and localization [17], etc. Consequently, an additional procedure to calculate the scaling factors is needed.

In the past few years, several approaches have been given in the literature for solving this problem. Some methods to scale mode shapes are based on updating a finite-element model of the structure using modal parameters estimated by OMA [18]. Another solution has been suggested by Bernal and Gunes [17] based on the assumption that the mass matrix of the structure or its inverse is known.

One way to estimate scaling factors is to modify the dynamic behavior of the structure by changing the stiffness and/or the mass and then perform operational modal analysis on both the original and the modified structure $[10,11,12]$. The methods based on dynamic modification use the modal parameters of both the modified and unmodified structure, so that a more extensive experimental testing procedure must be applied to estimate the scaling factors.

The class of scaling technique here denoted as the mass-change method [10, 11, 12, $19,20]$ consists of attaching masses to the points of the structure where the mode shapes 
of the unmodified structure are known. The user selects the number, the magnitude, and the location of the masses. The process is schematically shown in Fig. 1. For greater ease in the mass modification and the calculation of the scaling factors, lumped masses are often used, so that the mass-change matrix $[\Delta \mathrm{m}]$ becomes, in general, diagonal.

This approach has been validated by experimental testing of lab-tested structure scale models [19, 20], bridges [21], buildings [22], and mechanical systems [8, 9]. The mass-change method has also been used in FE-model updating where the modal parameters of the modified structure are used as additional information to correct the mass and the stiffness matrices of the system [23].

The original idea of this approach arises from Parloo et al. [10,11], who derived a closed form equation for estimating the scaling factors using a first-order approximation for the sensitivity of the natural frequencies with respect to the mass for light-damped structures. The application of this formula requires the frequency changes to be as small as possible and thus the mass modifications must be reasonably low. This paper suggests a mass change of around $5 \%$ of the total mass of the structure.

On the other hand, Brincker and Andersen [12] derived an expression that is accurate for relative large frequency shifts, provided that the changes in mode shapes are very small or zero. According to these authors, this condition is completely satisfied when the spatial distribution of mass modification is proportional to the mass of the original structure and thus, for this particular case, the proposed expression is exact.

The importance of the mass-change strategy, which means that the magnitude, the location and the number of masses to be attached to the structure must be defined, was presented by Aenlle et al. $[19,20]$. These authors showed that the accuracy achieved in the scaling-factor estimation depends not only on the accuracy reached in the modalparameter identification (as previously suggested by Parloo et al. [10, 11] and Brincker and Andersen [12]) but also on the mass-change strategy used to modify the dynamic behavior of the structure. The authors propose and validate a simple procedure to optimize the mass-change strategy, which uses the natural frequencies and mode shapes of the original structure as basic information. They also demonstrated that a mass change of $5 \%$ is not always sufficient for all mass-change configurations, but the number and location of the masses must also be considered. 
Another closed-form expression which does not impose limitations of the spatial distribution or the magnitude of the perturbation was proposed by Bernal [24]. The key feature of this formulation is the projection of the modes shapes of the modified system on the basis of the original structure. The formula considers changes in mode shapes, thus allowing for a relative large modification. Results from statistical simulations suggest that this formula not only is computationally attractive but can lead to improvements in accuracy when compared to the aforementioned alternatives.

A new formulation, denoted by the author "receptance base mode normalization" was proposed by Bernal [25] with which the scaling factors are estimated from an overdetermined system of equations whose coefficients are obtained by evaluating the pole residue form of the receptance matrix, at the eigenvalues of the unperturbed system. This approach is exact when a full set of modes is used.

An alternative to the mass-change method consists of changing the stiffness (stiffness-change method) which may be achieved by connecting some springs to the structure or other alternative devices such as cables or bars, at certain points of the structure where the mode shapes are known. Kathibi et al. [26] proposed the use of simultaneous mass and stiffness modification to estimate the scaling factors. Using a numerical example of a cantilever beam, they demonstrated that the combined massstiffness-change method can produce more accurate results compared to the mass change method, especially for the first modes.

In this paper, an exact set of equations is derived using the structural dynamic modification theory, from which all the existing exact and approximated formulations, used to estimate the scaling factors by the mass and stiffness-change methods, can be inferred. The assumptions made to establish the existing approximated formulations are studied and the accuracy of the results is investigated by performing simulations in several dynamic systems.

When a dynamic system is perturbed adding mass or stiffness, not only the natural frequencies and mode shapes are modified but also the scaling factors. The existing formulations to estimate the scaling factors of the unperturbed system do not need to know the scaling factors of the perturbed system. However, if the scaling factors of the perturbed system can be estimated with a reasonable low uncertainty, the accuracy 
achieved in the scaling factors of the original system can be checked. In this paper, an exact equation is proposed to estimate the scaling factors of the modified system which provides accurate results even for large mass changes.

\section{Structural dynamic modification}

In case of no damping, the equation of motion of a structure subjected to a force $\{\mathrm{p}(\mathrm{t})\}$ is given by:

$[\mathrm{m}] \cdot\{\ddot{\mathrm{u}}\}+[\mathrm{k}] \cdot\{\mathrm{u}\}=\{\mathrm{p}(\mathrm{t})\}$,

which provides the eigenvalue equation:

$[\mathrm{m}] \cdot\left\{\phi_{0}\right\} \cdot \omega_{0}^{2}=[\mathrm{k}] \cdot\left\{\phi_{0}\right\}$,

where $\left\{\phi_{0}\right\}$ and $\omega_{0}$ are the mass normalized mode shape and the natural frequency, respectively, and the subscript ' 0 ' indicates the un-perturbed or unmodified structure. The eigenvectors satisfy the orthogonality conditions:

$\left[\phi_{0}\right]^{\mathrm{T}} \cdot[\mathrm{m}] \cdot\left[\phi_{0}\right]=[\mathrm{I}]$,

$\left[\phi_{0}\right]^{\mathrm{T}} \cdot[\mathrm{k}] \cdot\left[\phi_{0}\right]=\left[\omega_{0}^{2}\right]$,

where $[\mathrm{I}]$ is the identity matrix.

If a dynamic modification given by the mass $[\Delta \mathrm{m}]$ and stiffness $[\Delta \mathrm{k}]$ matrices is applied to the structure, the new equation of motion becomes:

$$
([\mathrm{m}]+[\Delta \mathrm{m}]) \cdot\{\ddot{\mathrm{u}}\}+([\mathrm{k}]+[\Delta \mathrm{k}]) \cdot\{\mathrm{u}\}=\{\mathrm{p}(\mathrm{t})\}
$$

which provides the following eigenvalue equation for the i-th mode $[14,15,27,28]$ :

$$
\left([\mathrm{m}] \cdot\left[\phi_{0}\right]+[\Delta \mathrm{m}] \cdot\left[\phi_{0}\right]\right) \cdot\left\{\mathrm{A}_{\mathrm{i}}\right\} \cdot \omega_{\mathrm{Ii}}^{2}=\left([\mathrm{k}] \cdot\left[\phi_{0}\right]+[\Delta \mathrm{k}] \cdot\left[\phi_{0}\right]\right) \cdot\left\{\mathrm{A}_{\mathrm{i}}\right\},
$$

where $\omega_{\mathrm{Ii}}$ and $\left\{\mathrm{A}_{\mathrm{i}}\right\}$ are the natural frequency and the eigenvector, respectively, of the ith mode.

The mode shapes of the modified structure $\left[\phi_{\mathrm{I}}\right]$ are related to those of the original structure by: 
$\left[\phi_{\mathrm{I}}\right]=\left[\phi_{0}\right] \cdot[\mathrm{A}]$,

from Eq. (6), it follows that the modified mode shapes $\left\{\phi_{I}\right\}$ are expressed as a linear combination of the unmodified mode shapes $\left\{\phi_{0}\right\}$.

The un-scaled $\left\{\psi_{0}\right\}_{\mathrm{i}}$ and the scaled or mass normalized $\left\{\phi_{0}\right\}_{\mathrm{i}}$ mode-shape vectors, corresponding to $\mathrm{i}$-th mode, are related by the expression:

$\left\{\phi_{0 \mathrm{i}}\right\}=\alpha_{0 \mathrm{i}} \cdot\left\{\psi_{0 \mathrm{i}}\right\}$,

where the coefficient $\alpha_{0 \mathrm{i}}$ is the scaling factor of $\mathrm{i}$-th un-modified mode, which is a real number in case of no-damping. The corresponding equation for the modified structure is given by:

$\left\{\phi_{\mathrm{Ii}}\right\}=\alpha_{\mathrm{Ii}} \cdot\left\{\psi_{\mathrm{Ii}}\right\}$,

if Eqs. (7) and (8) are substituted in Eq. 6, it results in :

$\left[\psi_{\mathrm{I}}\right]=\left[\psi_{0}\right] \cdot[\mathrm{B}]$,

which relates the un-scaled mode shapes of both systems.

From Eqs. (6) and (9) can be inferred that the matrices [A] and [B] are related by the equation:

$[\mathrm{B}]=\left[\alpha_{0}\right] \cdot[\mathrm{A}] \cdot\left[\alpha_{1}\right]^{-1}$,

where $\left[\alpha_{0}\right]$ and $\left[\alpha_{1}\right]$ are diagonal matrices containing the scaling factors of the original and the modified structure, respectively. Thus, each term $B_{j i}$ of matrix $[B]$ is related to the corresponding term $\mathrm{A}_{\mathrm{ji}}$ of matrix $[\mathrm{A}]$ by:

$\mathrm{B}_{\mathrm{ji}}=\frac{\alpha_{0 \mathrm{j}} \cdot \mathrm{A}_{\mathrm{ji}}}{\alpha_{\mathrm{Ii}}}$

It should be noted that the exact relationships between the perturbed and the unpertubed systems given by Eqs. (6) and (9) are only possible if a full set of modes are used. In case of truncation, Eqs. (6) and (9) are approximated. 


\section{A set of equations for the scaling factors}

If Eq. (5) is pre-multiplied with the un-perturbed mass normalized mode shape vector $\left\{\phi_{0 \mathrm{j}}\right\}^{\mathrm{T}}$, it results in:

$$
\left\{\phi_{0 \mathrm{j}}\right\}^{\mathrm{T}} \cdot\left([\mathrm{m}] \cdot\left[\phi_{0}\right]+[\Delta \mathrm{m}] \cdot\left[\phi_{0}\right]\right) \cdot\left\{\mathrm{A}_{\mathrm{i}}\right\} \cdot \omega_{\mathrm{Ii}}^{2}=\left\{\phi_{0 \mathrm{j}}\right\}^{\mathrm{T}} \cdot\left([\mathrm{k}] \cdot\left[\phi_{0}\right]+[\Delta \mathrm{k}] \cdot\left[\phi_{0}\right]\right) \cdot\left\{\mathrm{A}_{\mathrm{i}}\right\},
$$

taking into account the orthogonality properties given by Eq. (3) and the projection of the perturbed mode shapes on the un-pertubed ones given by Eq. (6), Eq. (12) can be expressed as:

$$
\left(\omega_{0 \mathrm{j}}^{2}-\omega_{\mathrm{Ii}}^{2}\right) \cdot \mathrm{A}_{\mathrm{ji}}=\left\{\phi_{0 \mathrm{j}}\right\}^{\mathrm{T}} \cdot\left(\omega_{\mathrm{Ii}}^{2} \cdot[\Delta \mathrm{m}]-[\Delta \mathrm{k}]\right) \cdot\left\{\phi_{\mathrm{Ii}}\right\},
$$

where $\omega_{0 \mathrm{j}}$ is the $\mathrm{j}$-th natural frequency of the un-pertubed system.

Finally, if Eq. (11) is substituted in Eq.(13), it becomes:

$$
\left(\omega_{\mathrm{Ii}}^{2}-\omega_{0 \mathrm{j}}^{2}\right) \cdot \frac{\mathrm{B}_{\mathrm{ji}} \cdot \alpha_{\mathrm{Iij}}}{\alpha_{0 \mathrm{j}}}=\alpha_{0 \mathrm{j}} \cdot \alpha_{\mathrm{Ii}}\left\{\psi_{0 \mathrm{j}}\right\}^{\mathrm{T}} \cdot\left([\Delta \mathrm{k}]-\omega_{\mathrm{Ii}}^{2} \cdot[\Delta \mathrm{m}]\right) \cdot\left\{\psi_{\mathrm{Ii}}\right\},
$$

From which a closed form expression for the $\mathrm{j}$-th scaling factor is derived:

$$
\alpha_{0 \mathrm{j}}^{2}=\frac{\left(\omega_{0 \mathrm{j}}^{2}-\omega_{\mathrm{Ii}}^{2}\right) \cdot \mathrm{B}_{\mathrm{ji}}}{\left\{\psi_{0 \mathrm{j}}\right\}^{\mathrm{T}} \cdot\left(\omega_{\mathrm{Ii}}^{2} \cdot[\Delta \mathrm{m}]-[\Delta \mathrm{k}]\right) \cdot\left\{\psi_{\mathrm{Ii}}\right\}},
$$

Eq. (15) is a set of Nm (number of modes) equations which have to be fulfilled for any value of $\mathrm{i}$, i.e., there are as many expressions for the scaling factor of mode $\mathrm{j}$ as number of modes are considered in the analysis. Another interpretation is that the scaling factor of each mode has to fulfill simultaneously $\mathrm{Nm}$ conditions. Moreover, these set of equations are un-coupled, i.e., only the modal parameters of the j-th mode are needed in Eq. (15).

The relevance of Eq. (15) is that all the existing formulations for estimating the scaling factors can be derived from this equation.

Eq. (15) is an exact formulation for the scaling factor of the $\mathrm{j}$-th mode when a full set of modes are used. In case of a truncated set of modes, the only approximation is the necessary approximation of the matrix [B], in which case has to be estimated from the limited information given by the truncated set of modes, for instance by: 
$[\hat{\mathrm{B}}]=\left[\hat{\Psi}_{0}\right]^{-1}\left[\psi_{\mathrm{I}}\right]$

where $\left[\hat{\Psi}_{0}\right]^{-1}$ is the pseudo inverse of $\left[\Psi_{0}\right]$. The pseudo inverse can be obtained by singular value decomposition or by the corresponding least square solution

$$
\left[\hat{\Psi}_{0}\right]^{-1}=\left(\left[\Psi_{0}\right]^{\mathrm{T}} \cdot\left[\Psi_{0}\right]\right)^{-1} \cdot\left[\Psi_{0}\right]
$$

Since the pseudo inverse is an estimation, only the approximation $\left|\hat{\Psi}_{\mathrm{I}}\right|$ to $\left[\Psi_{\mathrm{I}}\right]$, given by:

$$
\left[\hat{\Psi}_{I}\right]=\left[\Psi_{0}\right] \cdot[\hat{B}],
$$

can be obtained. Therefore, if a truncated modal space is used in Eq. (16), none of the formulations based on this equation are strictly exact. The term "exact formulations" refers to the case where the matrix $[\mathrm{B}]$ is known.

On the other hand, except for closely spaced modes, the off-diagonal terms in matrix [B] are usually close to zero whereas the terms in the diagonal are close to one. Due to the modal truncation effect, reasonable accuracy is expected for the diagonal terms whereas a larger error is expected for the non-diagonal ones, which in turn depend on the number of modes used in the analysis. Thus, the equation with highest accuracy will normally be taking $i=j$ in Eq. (15) whereas the equations using $i \neq j$ will normally be less accurate.

\subsection{The extended projection approach (Ext-Pr)}

If a reasonable accuracy is expected in the terms of matrix [B], the set of equations (15) for the $\mathrm{j}$-th mode can be solved as an over-determined equation given by:

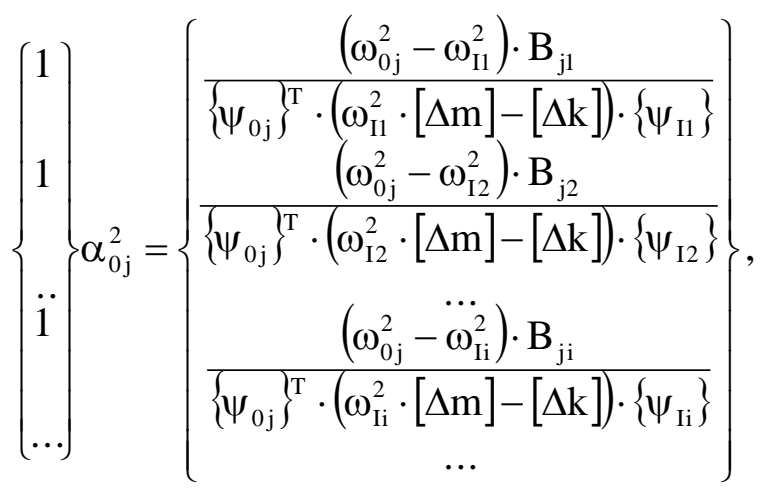


which is equivalent to:

$\alpha_{0 \mathrm{j}}^{2}=\frac{1}{\mathrm{Nm}} \sum_{\mathrm{i}=1}^{\mathrm{Nm}} \frac{\left(\omega_{0 \mathrm{j}}^{2}-\omega_{\mathrm{Ii}}^{2}\right) \cdot \mathrm{B}_{\mathrm{ji}}}{\left\{\psi_{0 \mathrm{j}}\right\}^{T} \cdot\left(\omega_{\mathrm{Ii}}^{2} \cdot[\Delta \mathrm{m}]-[\Delta \mathrm{k}]\right) \cdot\left\{\psi_{\mathrm{Ii}}\right\}}$,

from which can be inferred that the same weight is used for each equation. Due to the aforementioned large uncertainty expected in the terms out-off the diagonal in matrix [B], it is recommended to use a different weight for each equation, i.e.:

$\alpha_{0 j}^{2}=\sum_{\mathrm{i}=1}^{\mathrm{Nm}} \mathrm{W}_{\mathrm{i}} \cdot \frac{\left(\omega_{0 \mathrm{j}}^{2}-\omega_{\mathrm{Ii}}^{2}\right) \cdot \mathrm{B}_{\mathrm{ji}}}{\left\{\psi_{0 \mathrm{j}}\right\}^{\mathrm{T}} \cdot\left(\omega_{\mathrm{Ii}}^{2} \cdot[\Delta \mathrm{m}]-[\Delta \mathrm{k}]\right) \cdot\left\{\psi_{\mathrm{Ii}}\right\}}$.

Where the weight $\mathrm{W}_{\mathrm{i}}$ can, for example, be taken as:

$$
\mathrm{W}_{\mathrm{i}}=\frac{\mathrm{B}_{\mathrm{ji}}}{\sum_{\mathrm{i}=1}^{\mathrm{Nm} B_{j i}}}
$$

\section{Existing formulations with the mass change method}

In recent years, different authors have proposed equations to estimate the scaling factors by the mass change method $[10,11,12,28]$. As the equations given by Eq. (15) are exact formulations for the scaling factor, the assumptions made in the existing equations will be analysed.

\subsection{The Bernal projection equation (Ber-Pr)}

If Eq. (15) is particularized for the mass change method $([\Delta \mathrm{k}]=[0])$ and we take $\mathrm{i}=\mathrm{j}$, it results in:

$\alpha_{0 \mathrm{i}}^{2}=\frac{\left(\omega_{0 \mathrm{i}}^{2}-\omega_{\mathrm{Ii}}^{2}\right) \cdot \mathrm{B}_{\mathrm{ii}}}{\omega_{\mathrm{Ii}}^{2} \cdot\left\{\psi_{0 \mathrm{i}}\right\}^{\mathrm{T}} \cdot[\Delta \mathrm{m}] \cdot\left\{\psi_{\mathrm{Ii}}\right\}}$,

this equation coincides with that proposed by Bernal [24]. Therefore, the Bernal equation [24] is also an exact formulation.

This equation uses the diagonal terms of matrix $[\mathrm{B}]$ and it will always give very good estimates of the scaling factor even in cases where the mode shapes change significantly. 


\subsection{Brincker and Andersen equation (B\&A)}

The equation proposed by Brincker and Andersen is expressed as:

$$
\alpha_{0 \mathrm{i}}^{2}=\frac{\left(\omega_{0 \mathrm{i}}^{2}-\omega_{\mathrm{Ii}}^{2}\right)}{\omega_{\mathrm{Ii}}^{2} \cdot\left\{\psi_{0 \mathrm{i}}\right\}^{\mathrm{T}} \cdot[\Delta \mathrm{m}] \cdot\left\{\psi_{0 \mathrm{i}}\right\}},
$$

and it can be derived from Eq. (15) taking $\mathrm{i}=\mathrm{j}$ and regarding the matrix $[\mathrm{B}]$ as an identity matrix, in which case $\mathrm{B}_{\mathrm{ii}}=1$ and $\left\{\psi_{\mathrm{Ii}}\right\}=\left\{\psi_{0 \mathrm{i}}\right\}$.

\subsection{Enhanced Brincker and Andersen equation (E-B\&A)}

A better equation which enhances the accuracy provided by the original Brincker and Anderssen equation is also derived from Eq. (15), taking $\mathrm{i}=\mathrm{j}$, considering also the matrix $[\mathrm{B}]$ as an identity matrix but keeping both the original and the modified mode shapes, i.e.:

$$
\alpha_{0 \mathrm{i}}^{2}=\frac{\left(\omega_{0 \mathrm{i}}^{2}-\omega_{\mathrm{Ii}}^{2}\right)}{\omega_{\mathrm{Ii}}^{2} \cdot\left\{\psi_{0 \mathrm{i}}\right\}^{\mathrm{T}} \cdot[\Delta \mathrm{m}] \cdot\left\{\psi_{\mathrm{Ii}}\right\}} .
$$

\subsection{The Parloo et al. equation}

The equation of Parloo et al. is given by the expression:

$$
\alpha_{0 \mathrm{i}}^{2}=\frac{2\left(\omega_{0 \mathrm{i}}-\omega_{\mathrm{Ii}}\right)}{\omega_{0 \mathrm{i}} \cdot\left\{\psi_{0 \mathrm{i}}\right\}^{\mathrm{T}} \cdot[\Delta \mathrm{m}] \cdot\left\{\Psi_{0 \mathrm{i}}\right\}},
$$

and can be derived from Eq. (15), assuming the following simplifications: $i=j,[B]$ is an identity matrix and the following approximation is accepted:

$$
\frac{\left(\omega_{0}^{2}-\omega_{\mathrm{I}}^{2}\right)}{\omega_{\mathrm{I}}^{2}} \approx \frac{2\left(\omega_{0}-\omega_{\mathrm{I}}\right)}{\omega_{0}} .
$$

\subsection{The Bernal RBN equation (Ber-RBN)}

The un-scaled modified $i$-th mode shape can be expressed as a linear combination of the original mode shapes as:

$$
\left\{\psi_{\text {Ii }}\right\}=\left[\psi_{0}\right] \cdot\left\{\mathrm{B}_{\mathrm{i}}\right\}=\sum_{\mathrm{j}=1}^{\mathrm{Nm}}\left\{\psi_{0 \mathrm{j}}\right\} \cdot \mathrm{B}_{\mathrm{ji}}
$$


if the term $\mathrm{B}_{\mathrm{ji}}$ is isolated in Eq. (15) and substituted in Eq. (28), it becomes:

$$
\left\{\psi_{\mathrm{Ii}}\right\}=\sum_{\mathrm{j}=1}^{\mathrm{Nm}}\left\{\psi_{0 \mathrm{j}}\right\} \cdot \frac{\left\{\psi_{0 \mathrm{j}}\right\}^{\mathrm{T}} \cdot\left(\omega_{\mathrm{Ii}}^{2} \cdot[\Delta \mathrm{m}]-[\Delta \mathrm{k}]\right) \cdot\left\{\psi_{\mathrm{Ii}}\right\}}{\left(\omega_{0 \mathrm{j}}^{2}-\omega_{\mathrm{Ii}}^{2}\right)} \cdot \alpha_{0 \mathrm{j}}^{2},
$$

which also can be written as:

$$
\left\{\psi_{\mathrm{Ii}}\right\}=\sum_{\mathrm{j}=1}^{\mathrm{Nm}}\left\{\psi_{0 \mathrm{j}}\right\} \cdot \beta_{\mathrm{ji}} \cdot \alpha_{0 \mathrm{j}}^{2}
$$

where $\beta_{\mathrm{ji}}$ is a scalar given by:

$$
\beta_{\mathrm{ji}}=\frac{\left\{\psi_{0 \mathrm{j}}\right\}^{\mathrm{T}} \cdot\left(\omega_{\mathrm{Ii}}^{2} \cdot[\Delta \mathrm{m}]-[\Delta \mathrm{k}]\right) \cdot\left\{\psi_{\mathrm{Ii}}\right\}}{\left(\omega_{0 \mathrm{j}}^{2}-\omega_{\mathrm{Ii}}^{2}\right)} .
$$

Eq. 30 coincides with that proposed by Bernal [25] and as the author states, except for truncation, it is also an exact formulation.

If Eq. (30) is applied for all the modes considered in the analysis, the following over-determined system of equations $(\mathrm{m} \times \mathrm{Nm}$ equations, where $\mathrm{m}$ is the number of measuring points, and $\mathrm{Nm}$ are the number of modes ) results:

$$
\left(\begin{array}{c}
\left\{\psi_{\mathrm{I} 1}\right\} \\
\left\{\psi_{\mathrm{I} 2}\right\} \\
\ldots \\
\left\{\psi_{\mathrm{Ii}}\right\} \\
\ldots
\end{array}\right)=\left(\begin{array}{c}
\sum_{\mathrm{j}=1}^{\mathrm{Nm}}\left\{\psi_{0 \mathrm{j}}\right\} \cdot \beta_{\mathrm{j} 1} \cdot \alpha_{0 \mathrm{j}}^{2} \\
\sum_{\mathrm{j}=1}^{\mathrm{Nm}}\left\{\psi_{0 \mathrm{j}}\right\} \cdot \beta_{\mathrm{j} 2} \cdot \alpha_{0 \mathrm{j}}^{2} \\
\ldots . \\
\sum_{\mathrm{j}=1}^{\mathrm{Nm}}\left\{\psi_{0 \mathrm{j}}\right\} \cdot \beta_{\mathrm{ji}} \cdot \alpha_{0 \mathrm{j}}^{2} \\
\ldots
\end{array}\right) .
$$

If we define a new diagonal matrix $\left[\beta_{\mathrm{i}}\right]$ containing the term $\beta_{\mathrm{ji}}$ in the $\mathrm{j}$-th row, Eq. (32) can be written in a more compact form as:

$$
\left(\begin{array}{c}
\left\{\psi_{\text {I1 }}\right\} \\
\left\{\psi_{\text {I2 }}\right\} \\
\ldots \\
\left\{\psi_{\text {II }}\right\} \\
\ldots
\end{array}\right)=\left(\begin{array}{c}
{\left[\psi_{0}\right] \cdot\left[\beta_{1}\right]} \\
{\left[\psi_{0}\right] \cdot\left[\beta_{2}\right]} \\
\ldots \\
{\left[\psi_{0}\right] \cdot\left[\beta_{\mathrm{i}}\right]} \\
\ldots
\end{array}\right)\left\{\begin{array}{c}
\alpha_{01}^{2} \\
\alpha_{02}^{2} \\
\ldots \\
\alpha_{0 \mathrm{j}}^{2} \\
\ldots
\end{array}\right\} .
$$




\section{The scaling factors of the modified structure}

Pre-multiplication of Eq. (5) by $\left\{\phi_{\mathrm{Ij}}\right\}^{\mathrm{T}}=\left(\left[\phi_{0}\right]\left\{\mathrm{A}_{\mathrm{j}}\right\}\right)^{\mathrm{T}}$ gives the following equation:

$$
\left\{\mathrm{A}_{\mathrm{i}}\right\}^{\mathrm{T}} \cdot\left(\left[\omega_{0}^{2}\right]-\omega_{\mathrm{Ii}}^{2} \cdot[\mathrm{I}]\right) \cdot\left\{\mathrm{A}_{\mathrm{i}}\right\}+\left\{\phi_{\mathrm{Ii}}\right\}^{\mathrm{T}} \cdot\left([\Delta \mathrm{k}]-\omega_{\mathrm{Ii}}^{2} \cdot[\Delta \mathrm{m}]\right) \cdot\left\{\phi_{\mathrm{Ii}}\right\}=\{0\},
$$

if Eq. (8) is substituted into Eq. (34), it becomes:

$$
\left\{\mathrm{A}_{\mathrm{i}}\right\}^{\mathrm{T}} \cdot\left(\left[\omega_{0}^{2}\right]-\omega_{\mathrm{Ii}}^{2} \cdot[\mathrm{I}]\right)\left\{\mathrm{A}_{\mathrm{i}}\right\}+\alpha_{\mathrm{Ii}}^{2} \cdot\left\{\psi_{\mathrm{Ii}}\right\}^{\mathrm{T}} \cdot\left([\Delta \mathrm{k}]-\omega_{\mathrm{Ii}}^{2}[\Delta \mathrm{m}]\right) \cdot\left\{\psi_{\mathrm{Ii}}\right\}=\{0\} \cdot
$$

Finally, the scaling factor corresponding to the $\mathrm{i}$-th mode is given by:

$$
\alpha_{\mathrm{Ii}}^{2}=\frac{\left\{\mathrm{A}_{\mathrm{i}}\right\}^{\mathrm{T}} \cdot\left(\left[\omega_{0}^{2}\right]-\omega_{\mathrm{Ii}}^{2} \cdot[\mathrm{I}]\right) \cdot\left\{\mathrm{A}_{\mathrm{i}}\right\}}{\left\{\psi_{\mathrm{Ii}}\right\}^{\mathrm{T}} \cdot\left(\omega_{\mathrm{Ii}}^{2} \cdot[\Delta \mathrm{m}]-[\Delta \mathrm{k}]\right) \cdot\left\{\psi_{\mathrm{Ii}}\right\}},
$$

which is the exact solution for the scaling factor of the i-th modified mode shape, and can also be expressed as:

$$
\alpha_{\mathrm{Ii}}^{2}=\frac{\sum_{\mathrm{j}=1}^{\mathrm{Nm}}\left(\omega_{0 \mathrm{j}}^{2}-\omega_{\mathrm{Ii}}^{2}\right) \cdot \mathrm{A}_{\mathrm{ji}}^{2}}{\left\{\psi_{\mathrm{Ii}}\right\}^{\mathrm{T}} \cdot\left(\omega_{\mathrm{Ii}}^{2} \cdot[\Delta \mathrm{m}]-[\Delta \mathrm{k}]\right) \cdot\left\{\psi_{\mathrm{Ii}}\right\}} .
$$

Eq. (37) does not have practical application because we cannot estimate the terms of matrix $[\mathrm{A}]$ from the un-scaled mode shapes.

On the other hand, if a mass change is applied to a structure resulting in a new mass matrix $[\mathrm{m}]+[\Delta \mathrm{m}]$, the $\mathrm{i}$-th scaling factor of the modified structure is given by:

$$
\alpha_{\mathrm{Ij}}^{2}=\frac{1}{\left\{\psi_{\mathrm{Ij}}\right\}^{T} \cdot([\mathrm{m}]+[\Delta \mathrm{m}]) \cdot\left\{\psi_{\mathrm{Ij}}\right\}},
$$

As the mass matrix $[\mathrm{m}]$ is not known, the term $\left\{\psi_{\mathrm{Ij}}\right\}^{\mathrm{T}} \cdot[\mathrm{m}] \cdot\left\{\psi_{\mathrm{Ij}}\right\}$ can be expressed as:

$$
\left\{\psi_{\mathrm{Ij}}\right\}^{\mathrm{T}} \cdot[\mathrm{m}] \cdot\left\{\psi_{\mathrm{Ij}}\right\}=\left\{\mathrm{B}_{\mathrm{j}}\right\}^{\mathrm{T}} \cdot\left[\psi_{0}\right]^{\mathrm{T}} \cdot[\mathrm{m}] \cdot\left[\psi_{0}\right] \cdot\left\{\mathrm{B}_{\mathrm{j}}\right\}=\left\{\mathrm{B}_{\mathrm{j}}\right\}^{\mathrm{T}} \cdot\left[\alpha_{0}^{2}\right]^{-1} \cdot\left\{\mathrm{B}_{\mathrm{j}}\right\},
$$

or alternatively :

$$
\left\{\psi_{\mathrm{Ij}}\right\}^{\mathrm{T}} \cdot[\mathrm{m}] \cdot\left\{\psi_{\mathrm{Ij}}\right\}=\sum_{\mathrm{k}=1}^{\mathrm{Nm}} \mathrm{B}_{\mathrm{kj}}^{2} \frac{1}{\alpha_{0 \mathrm{k}}^{2}} .
$$


If Eq. (40) is substituted in Eq. (38), it results:

$$
\alpha_{\mathrm{Ij}}^{2}=\frac{1}{\sum_{\mathrm{k}=1}^{\mathrm{Nm}} \frac{\mathrm{B}_{\mathrm{kj}}^{2}}{\alpha_{0 \mathrm{k}}^{2}}+\left\{\psi_{\mathrm{Ij}}\right\}^{\mathrm{T}} \cdot[\Delta \mathrm{m}] \cdot\left\{\psi_{\mathrm{Ij}}\right\}}
$$

In case of systems with closely spaced modes, at least the contribution of the terms corresponding to the near modes must be used in Eq. 41. In case of systems with wellseparated modes, the following approximation provides a reasonable accuracy.

$$
\alpha_{\mathrm{Ij}}^{2} \approx \frac{\alpha_{0 \mathrm{j}}^{2}}{\mathrm{~B}_{\mathrm{jj}}^{2}+\alpha_{0 \mathrm{j}}^{2} \cdot\left\{\psi_{\mathrm{Ij}}\right\}^{T} \cdot[\Delta \mathrm{m}] \cdot\left\{\psi_{\mathrm{Ij}}\right\}},
$$

If the scaling factors of both the original and the modified structure are known, the matrix [A] can be estimated using Eq. (10) and, subsequently, the accuracy of the results can be checked because the following equation must be fulfilled for the mass change method, i.e.:

$$
\left[\omega_{I}^{2}\right]=[A]^{T} \cdot\left[\omega_{0}^{2}\right] \cdot[A]
$$

and

$$
\left\lfloor\omega_{I}^{2}\right\rfloor=[A]^{T} \cdot\left\lfloor\omega_{0}^{2}\right\rfloor \cdot[A]+[A]^{T} \cdot\left[\Phi_{0}\right]^{T} \cdot[\Delta K] \cdot\left[\Phi_{0}\right] \cdot[A] .
$$

for the stiffness change method.

\section{Numerical examples}

The scaling-factor accuracy achieved with the expressions discussed in this paper has been studied by performing one thousand simulations on an un-damped plate model [29] with dimensions $519.3 \times 320 \times 20$ mm and meshed with 99 nodes (see Fig. 2) and the following material properties: density $\rho=1.180 \mathrm{~kg} / \mathrm{m} 3$, Young modulus $E=3300$ $\mathrm{MPa}$ and Poisson ratio $v=0.36$.

The natural frequencies and the scaling factors, corresponding to mode shapes normalized to unity length, are shown in Table 1 . This plate has a variable modal distribution with very closely spaced modes (for example the $1^{\text {st }}$ and $2^{\text {nd }}$ modes are separated $1 \mathrm{~Hz}$ and the $4^{\text {th }}$ and $5^{\text {th }}$ separated $5.5 \mathrm{~Hz}$ ) and widely separated modes (for example modes 3 and 6). The simulations were performed considering 18 sensors 
located at DOF's: $1,5,9,19,23,27,37,41,45,55,59,63,73,77,81,91,95$ and 99, placing masses randomly at 12 of the 18 measurement points. A total mass change of $2 \%, 5 \%$ and $15 \%$ of the mass of the structure, respectively, was considered in the simulations. The results of the first three modes are presented in this paper but the modal parameters of the first five modes were considered in the simulations.

Simulations were initially carried out without considering errors in the modal parameters. However, as the largest source of error in the estimation of the scaling constants is the uncertainty on the modal parameters, noisy conditions were also simulated considering an identification error in the natural frequencies as:

$$
\omega_{\text {sim }}=\omega_{\text {exact }} \cdot\left(1+\frac{1}{1000} \cdot \alpha_{\omega}\right)
$$

and in each component of the mode shapes as:

$$
\psi_{\text {sim }}=\psi_{\text {exact }} \cdot\left(1+\frac{2}{100} \cdot \alpha_{\psi}\right)
$$

where $\alpha_{\omega}$ and $\alpha_{\psi}$ are random variables with a uniform distribution with limits of [-1 $1]$.

When the scaling factors are estimated with the extended projection approach, the terms $i \neq j$ are much less accurate than the term $i=j$, mainly in noisy conditions. In the simulations, only the terms with $\mathrm{B}_{\mathrm{ij}}>0.2$ were considered.

The errors in the scaling factor for the first three modes, when errors are not considered in the modal parameters, are shown in Fig. 3. In this case, the uncertainty is only due to modal truncation and the approximations assumed in the derivation of the approximated equations (Parloo, B\&A and E-B\&A). Different scatter has been obtained for each mode, but this is expected because the mass change location is not optimal for all the modes considered (see [19]). As regards the influence of the mass change magnitude, all the equations provide better results for small mass changes. From Fig.3 can be concluded that the approximated equations only provides a reasonable accuracy in separated modes, whereas the exact formulations (Bernal Projection, Bernal RBN and the extended proyection approach) are considerably more accurate than the approximated equations in both closely and separated modes. 
The statistical distribution of the results provided by the exact formulations for a mass-change of $5 \%$ is shown in Fig. 4 where it can be observed that the accuracy obtained with all the exact formulations are very similar.

As regards the simulations considering noisy conditions, the results obtained with the exact formulations are presented in Fig. 5 to 8, where the statistical distribution correspond to mass-changes of $15 \%$.

The results presented in Fig. 5, which correspond to simulations not considering errors in the modal parameters, are included for comparison with the results of other simulations. All the exact formulations provide similar results, as it can be observed in the statistical distributions.

The results corresponding to errors in the natural frequencies $\left(\varepsilon_{\omega}=0.1 \%\right)$, are shown in Fig. 6. Again, all the exact formulations provide similar results, as it can be seen in the statistical distribution of the results. When the scaling factors are estimated with the Bernal RBN equation and the extended projection approach, some outlier appear for mode 3 and mass-change of $15 \%$. From the statistical distributions it can be seen that there is a tendency to a slightly smaller bias for the Bernal RBN equation compared to the other approaches. On the other hand, all the equations provide better accuracy as large is the mass change magnitude

Fig. 7 shows the results when only errors in the mode shapes $\left(\varepsilon_{\psi}=2 \%\right)$ are considered. All the exact formulations provide similar results and there is not a significant influence of the mass change magnitude. In this case, a significant number of outliers were obtained for mode 3 and a mass-change of $15 \%$, which means that the Bernal RBN equation and the extended projection approach are sensitive to errors in the mode shapes. Again, there is a clear tendency to smaller bias for the Bernal RBN equation (especially for mode three).

Finally, Fig. 8 presents the results corresponding to errors in natural frequencies and mode shapes. The same conclusions on the magnitude of the errors, as those obtained considering only errors in natural frequencies, can be extracted, which means that the main source of uncertainty come from the errors in the natural frequencies. Again, a significant number of outliers were obtained for mode 3 and a mass-change of $15 \%$ with the Bernal RBN equation and the extended projection approach. 
The scaling factors of the modified structure were estimated with Eq. 41 taking as scaling factors of the unperturbed structurethose estimated with the Bernal projection approach. The errors obtained with the simulations for every mass change are presented

in Table 2. Less error is obtained in separated modes (mode 3) than for the closely spaced modes ( 1 and 2 ) and the error increases with increasing mass change. The error is larger in noisy conditions than the case when errors are not considered in the modal parameters. On the other hand, the maximum error is approximately $20 \%$ for mass changes of $2 \%$ and $5 \%$ of the total mass and $30 \%$ for mass changes of $15 \%$.

If the results obtained for the scaling factors of both the un-perturbed and perturbed structure are compared, a better accuracy is obtained for the scaling factors of the unmodified structure. However, this is expected because from Eq. (41) it can be inferred that, besides the scaling factors of the un-perturbed structure, the terms of the $\mathrm{j}$-th column of matrix $[\mathrm{B}]$ and the terms of the $\mathrm{j}$-th modified mode shape, contribute to the uncertainty of scaling factor $\alpha_{\mathrm{Ij}}$.

\section{Conclusions}

Two new exact formulations for estimating the scaling factors in operational modal analysis, one for the non-modified structure and another one for the modified structure, have been proposed and validated by simulations on a plate model.

The exact formulations are always more accurate than the approximated equations and all of them provide similar results for small mass changes.

The approximated formulations are not recommended for systems with closely spaced modes.

When no errors are considered in the modal parameters, the uncertainty on the scaling factor with all the equations used in this paper increase with increasing mass change. Under conditions of noise on the modal parameter estimates, the results provided by the exact formulations are more accurate for large mass changes. 
The Bernal projection formula provides the overall smallest random errors on the scaling factors, as the Bernal RBN and the extended projection formula has a tendency to produce more noise (outliers).

The Bernal projection formula however has the largest bias, the Bernal RBN has the smallest bias and the extended projection formula has a bias in between the Bernal projection formula and the Bernal RBN.

The scaling factors of the un-perturbed structure can be estimated with a better accuracy that those of the perturbed structure. The Eq. (41) provides a better accuracy for separated modes than for closely spaced modes.

\section{Acknowledgements}

The partial economic support given by the Spanish Ministry of Education through the project BIA2008-06816-C02-01and the European Social Fund (grant BES-200612566) is gratefully appreciated.

\section{References}

[1] R. Cantieni, Experimental Methods Used in System Identification of Civil Engineering Structures, Proceedings of the International Operational Modal Analysis Conference (IOMAC), Copenhagen, 2005, pp. 249-260.

[2] A. Cunha, and E. Caetano, From Input-Output to Output-Only Modal Identification of Civil Engineering, Proceedings of the International Operational Modal Analysis Conference (IOMAC), Copenhagen, Denmark, 2005, pp. 11-27.

[3] R. Brincker, C. Ventura, and P. Andersen, Why Output-Only Modal Testing is a Desirable Tool for a Wide Range of Practical Applications, Proceedings of the International Modal Analysis Conference (IMAC XXI), Orlando, USA, 2003, paper 265 .

[4] N. Møller, R. Brincker, H. Herlufsen and P. Andersen, Modal Testing Of Mechanical Structures Subject To Operational Excitation Forces, Proceedings of 
The 19th International Modal Analysis Conference (IMAC), Kissimmee, Florida, USA, 2001, pp. 262-269.

[5] R. Brincker, P. Andersen, N. Møller and H. Herlufsen, Output Only Testing Of a Car Body Subject To Engine Excitation, Proceedings of the 18th International Modal Analysis Conference (IMAC), San Antonio, Texas, USA, 2001, pp. 786792.

[6] F. Magalhaes, A. Cunha and E. Caetano, Operational modal analysis and finite element model correlation of the Braga Stadium suspended roof, Engineering Structures, 30, 2008, pp. 1688-1698.

[7] F. Magalhaes, E. Caetano and A. Cunha, Online Identification of The Modal Parameters of a Long Span Arch Bridge. Mechanical Systems and Signal Processing, 23, 2009, pp. 316-329.

[8] E. Parloo, P. Guillaume, J. Anthonis, W. Heylen and N. Swevers, Modelling of Sprayer Boom Dynamics by Means of Maximum Likelihood Identification Techniques, Part 1: A Comparison of Input-output and Output-only Modal Testing. Biosystem Engineering, 85 (2), 2003, pp. 163-171.

[9] E. Parloo, P. Guillaume, J. Anthonis, W. Heylen and N. Swevers, Modelling of Sprayer Boom Dynamics by Means of Maximum Likelihood Identification Techniques, Part 2: Sensitivity-based Mode Shape Normalization. Biosystem Engineering, 85(2), 2003, pp. 291-298.

[10] E. Parloo, P. Verboven, P. Guillaume and M. Van Overmeire, Sensitivity- Based Operational Mode Shape Normalization. Mechanical Systems and Signal Processing, 16 , 2002, pp. 757-767.

[11] E. Parloo, P. Verboven, P. Guillaume, and M. Van Overmeire, SensitivityBased mass normalization of mode shape estimates from output-only data. Proc. Int. conf. on Structural System Identification, 2001, pp. 267-636.

[12] R. Brincker and P. Andersen, A Way of Getting Scaled Mode Shapes in Output Only Modal Analysis, Proceedings of the International Modal Analysis Conference (IMAC) XXI, Orlando, USA, 2003, paper 141. 
[13] G. Coppotelli, On the estimate of the FRFs from operational data. Mechanical Systems and Signal Processing, 23, 2008, pp. 288-299.

[14] W. Heylen, M. Lammens and P. Sas, Modal Analysis: Theory and Testing, Katholieke Universiteit Leuven, Belgium, 1997.

[15] N.M.M. Maia and J.M.M. Silva, Theoretical and Experimental Modal Analysis. Research Studies Press L.T.D., England 1997.

[16] D.J. Ewins, Modal Testing: Theory and Practice, Research Studies Press, L.T.D., England, 2000.

[17] D. Bernal and B. Gunes, Damage Localization in Output-Only Systems: A Flexibility Based Approach. Proc. Of the International Modal Analysis Conference (IMAC) XX, Los Angeles, California, 2002, pp. 1185-191.

[18] C.E. Ventura, J.F. Lord, M. Turek, R. Brincker, P. Andersen and E. Dascotte, FEM Updating of Tall Buildings Using Ambient Vibration Data. Proceedings of The 6th International Conference on Structural Dynamics (EURODYN), Paris, France. 2005.

[19] M. López Aenlle, P. Fernández, R. Brincker and A. Fernández Canteli, Scaling Factor Estimation using an Optimized Mass Change Strategy. Mechanical Systems and Signal Processing, (2010). Vol. 24, pp. 3061-3074.

[20] P. Fernández, M. López Aenlle, L. Villa and R. Brincker, Scaling Factor Estimation using an Optimized Mass Change Strategy. Part 2: Experimental Results, Proceedings of the International Operational Modal Analysis Conference (IOMAC), Copenhagen, Denmark, 2007, pp 429-436.

[21]E. Parloo, B. Cauberghe, F. Benedettini, R. Alaggio and P. Guillaume, Sensivity-based Operatioonal Mode Shape Normalization: Application to a Bridge. Mechanical Systems and Signal Processing, 19, 2005, pp. 43-55.

[22] R. Brincker, J. Rodrigues and P. Andersen, Scaling the Mode Shapes of a Building Model by Mass Changes, Proceedings of The 22nd International Modal Analysis Conference (IMAC), Detroit, Michigan, USA, 2004, pp. 119-126. 
[23] H. Shahverdi, C. Mares and J.E. Mottershead, Model structure correction and updating of aeroengine casings using fictitious mass modifications. Journal of Mechanical Engineering Science, 12, 2005, pp. 19-30.

[24] D. Bernal, Modal Scaling from Known Mass Perturbations. Journal of Engineering Mechanics, 130 (9), 2004, pp. 1083-1088.

[25] D. Bernal, A Receptance Based Formulation for Modal Scaling using Mass Perturbations. Mechanical Systems and Signal Processing, (2010), doi:10.1016/j.ymssp.2010.08.004

[26] M.M. Khatibi, M.R. Ashory and A. Malekjafarian, Scaling of Mode Shapes Using Mass-Stiffness Change Method. Proceedings of the International Operational Modal Analysis Conference (IOMAC), Copenhagen,Denmark, 2009, pp. 699-706.

[27] A. Sestiere, Structural Dynamic Modification. Academy Proceedings in Engineering Sciences (Sadhana), 3 (25), 2000, pp. 247-259.

[28] M. López Aenlle, R. Brincker and A. Fernández Canteli, Some Methods to Determine Scaled Mode Shapes in Natural Input Modal Analysis. Proceedings of the International Modal Analysis Conference (IMAC XXIII), Orlando, USA. 2005, paper 154 .

[29] Don L. Gregory and David O. Smallwood, Experimental Results of the IES Modal Plate. The Journal of Environmental Sciences, vol XXXII (6), 1989, pp. $15-21$. 
Editable Figure Captions:

Figure 1. The mass change method.

Figure 2. Plate model used in the simulations.

Figure 3. Errors obtained in the simulations. Not errors considered in the modal parameters.

Figure 4 Statistical distribution of the simulations corresponding to a mass-change of $5 \%$. Not errors considered in the simulations.

Figure 5. Results of simulations when no error is considered in the modal parameters (up). Statistical distribution corresponding to a mass-change of $15 \%$ (down).

Figure 6 Results of simulations when errors $(\varepsilon \omega=0.1 \%)$ are considered in the natural frequencies (up). Statistical distribution corresponding to a mass-change of $15 \%$ (down).

Figure 7 Results of simulations when errors $\left(\varepsilon_{\psi}=2 \%\right)$ are considered in the mode shapes (up). Statistical distribution corresponding to a mass-change of $15 \%$ (down).

Figure 8 Results of simulations when errors are considered in the natural frequencies $\left(\varepsilon_{\omega}=0.1 \%\right)$ and mode shapes $\left(\varepsilon_{\psi}=2 \%\right)$ (up). Statistical distribution corresponding to a mass-change of $15 \%$ (down).

Editable Tables Caption

Table 1. Modal properties of the plate.

Table 2. Errors obtained in the scaling factors of the modified structure. 
UNMODIFIED STRUCTURE

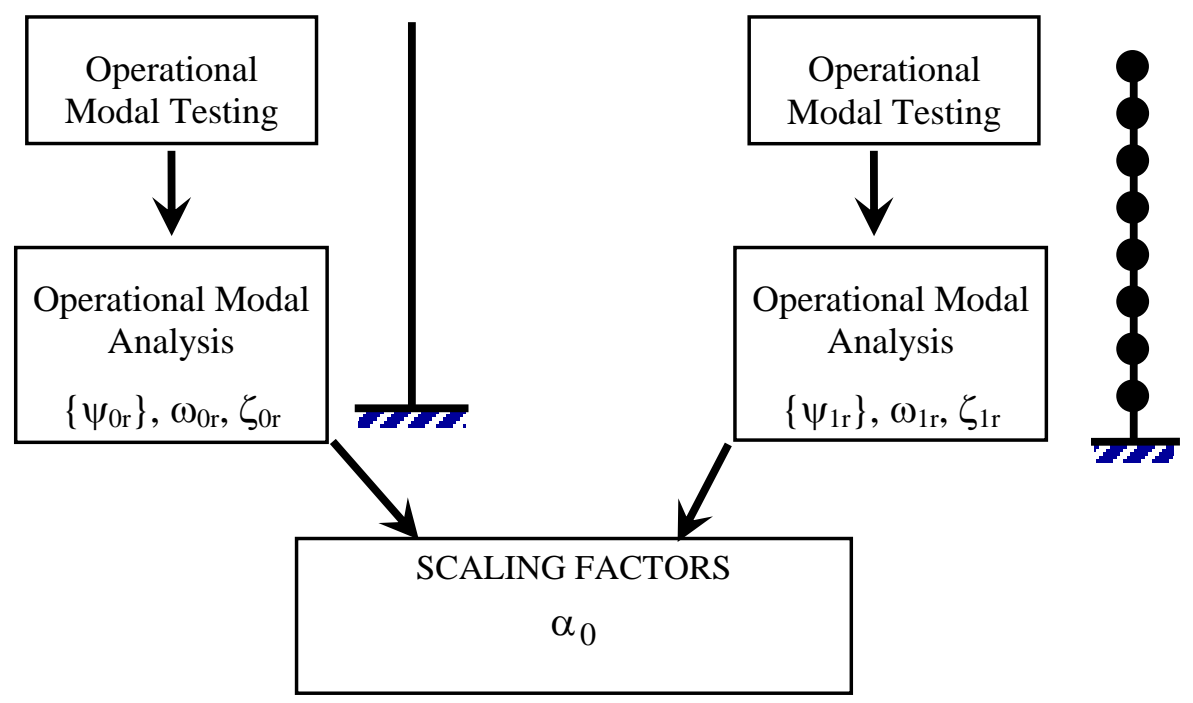

Figure 1. The mass change method. 


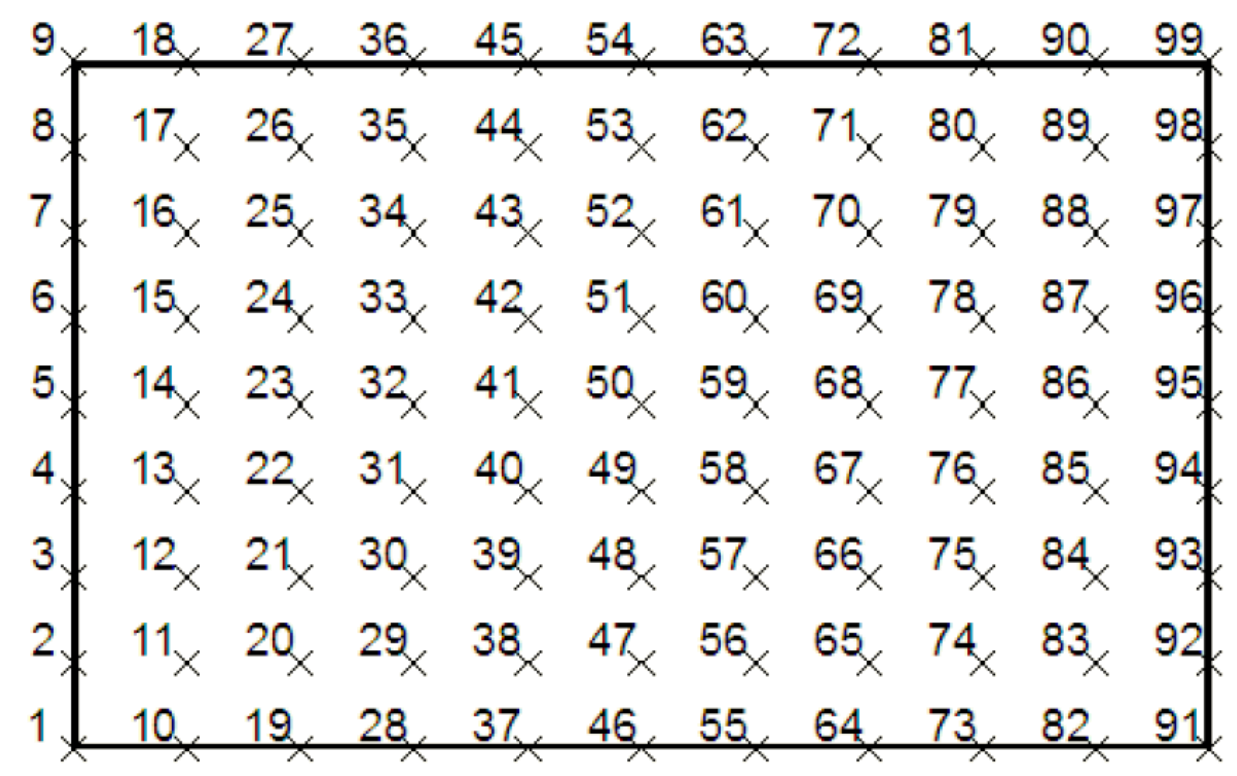

Figure 2. Plate model used in the simulations. 

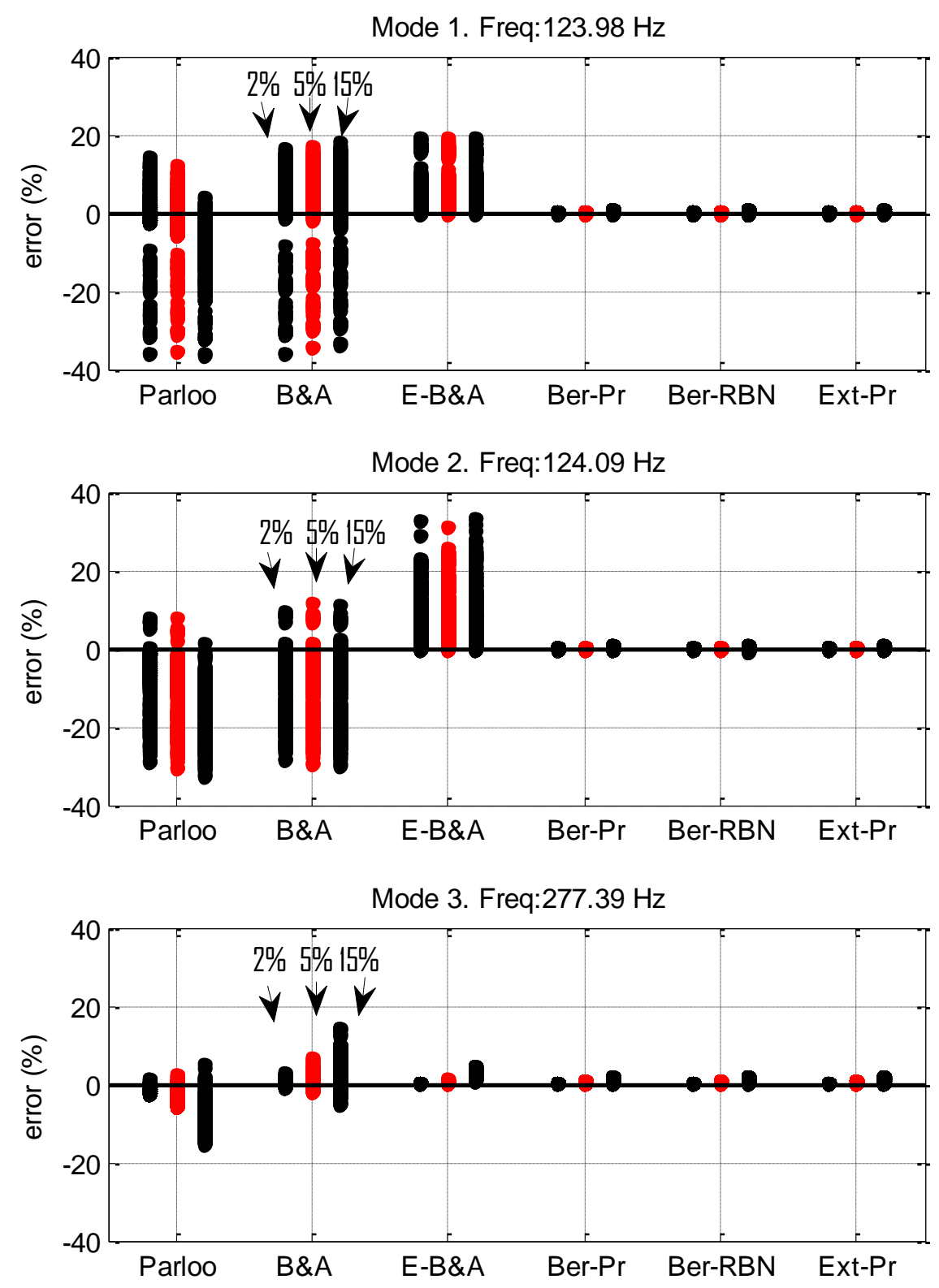

Figure 3. Errors obtained in the simulations. Not errors considered in the modal parameters. 

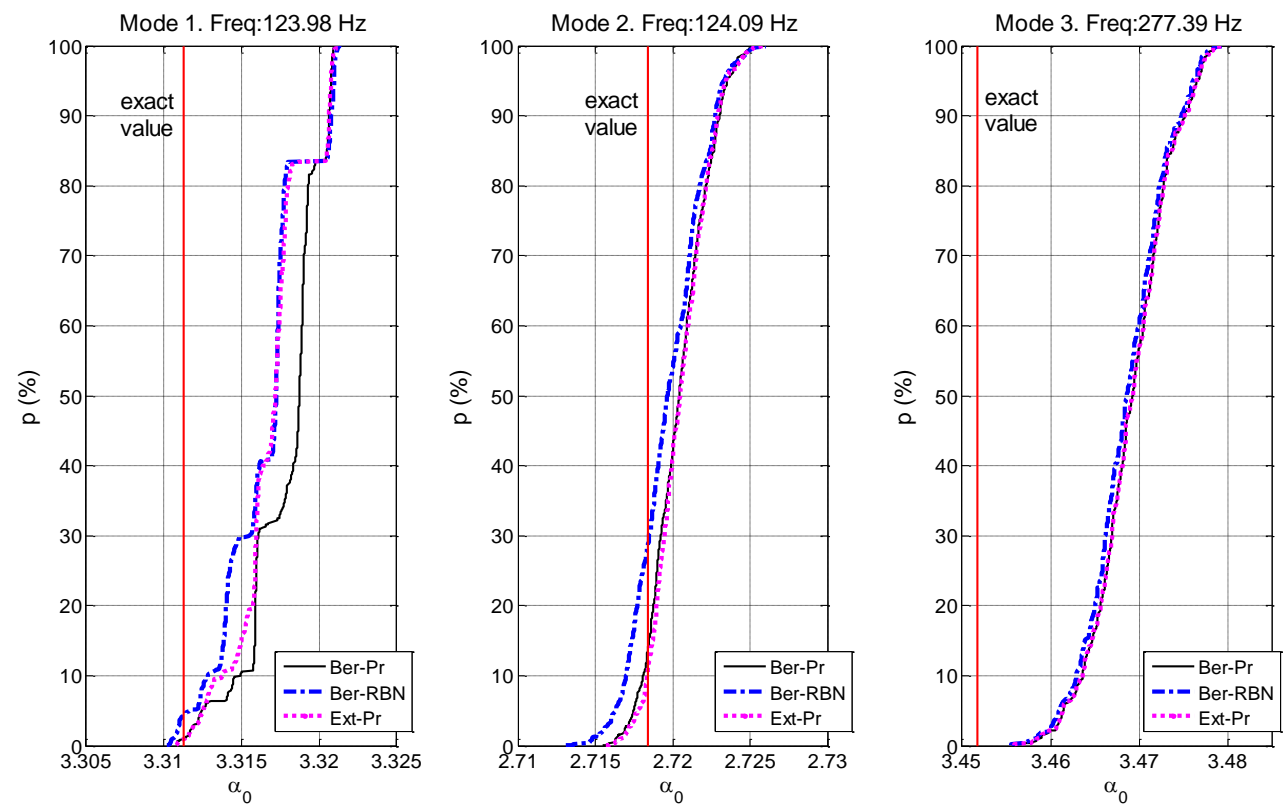

Fig. 4 Statistical distribution of the simulations corresponding to a mass-change of 5\%. Not errors considered in the simulations. 

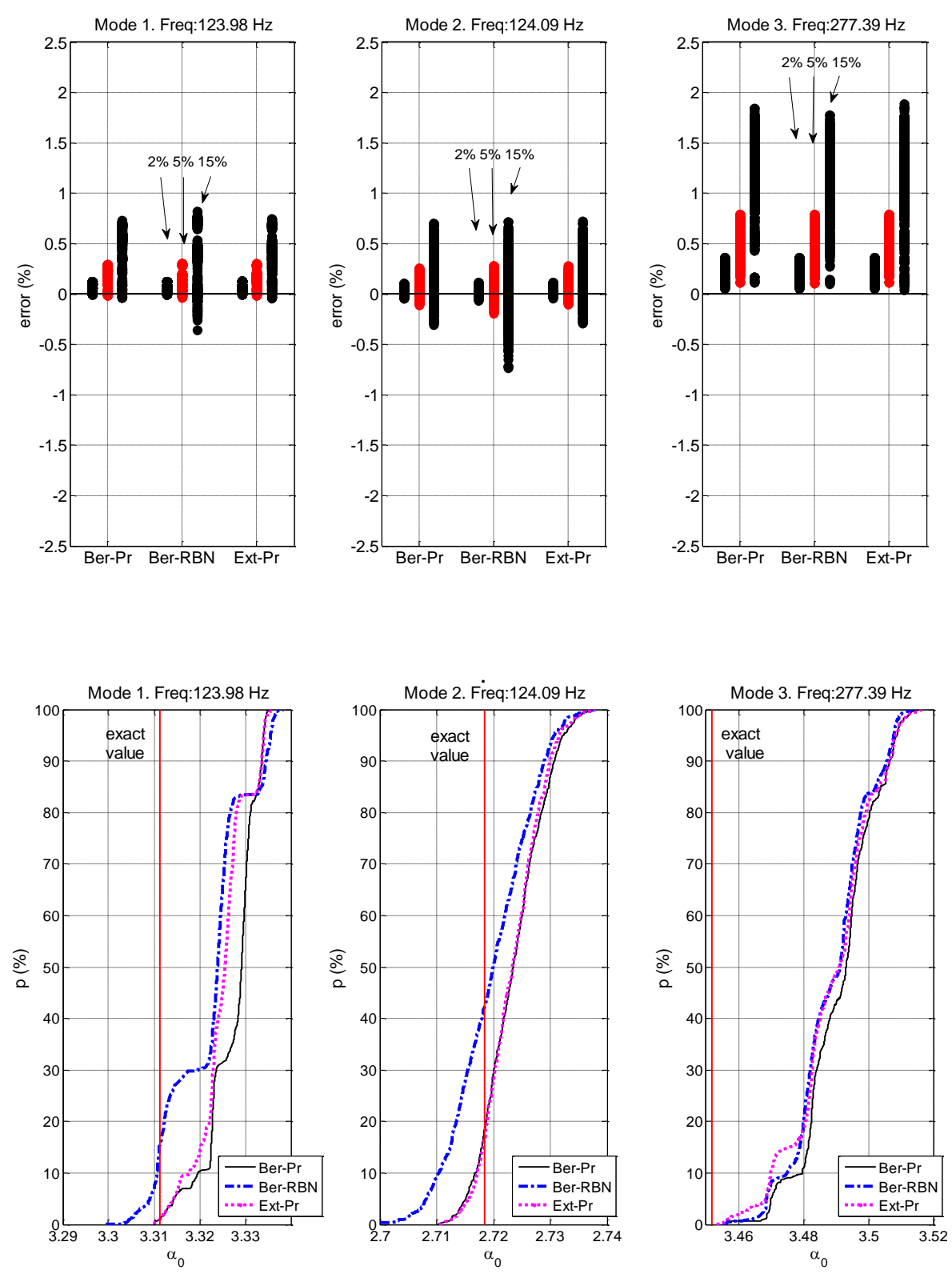

Fig. 5. Results of simulations when no error is considered in the modal parameters (up). Statistical distribution corresponding to a mass-change of $15 \%$ (down). 

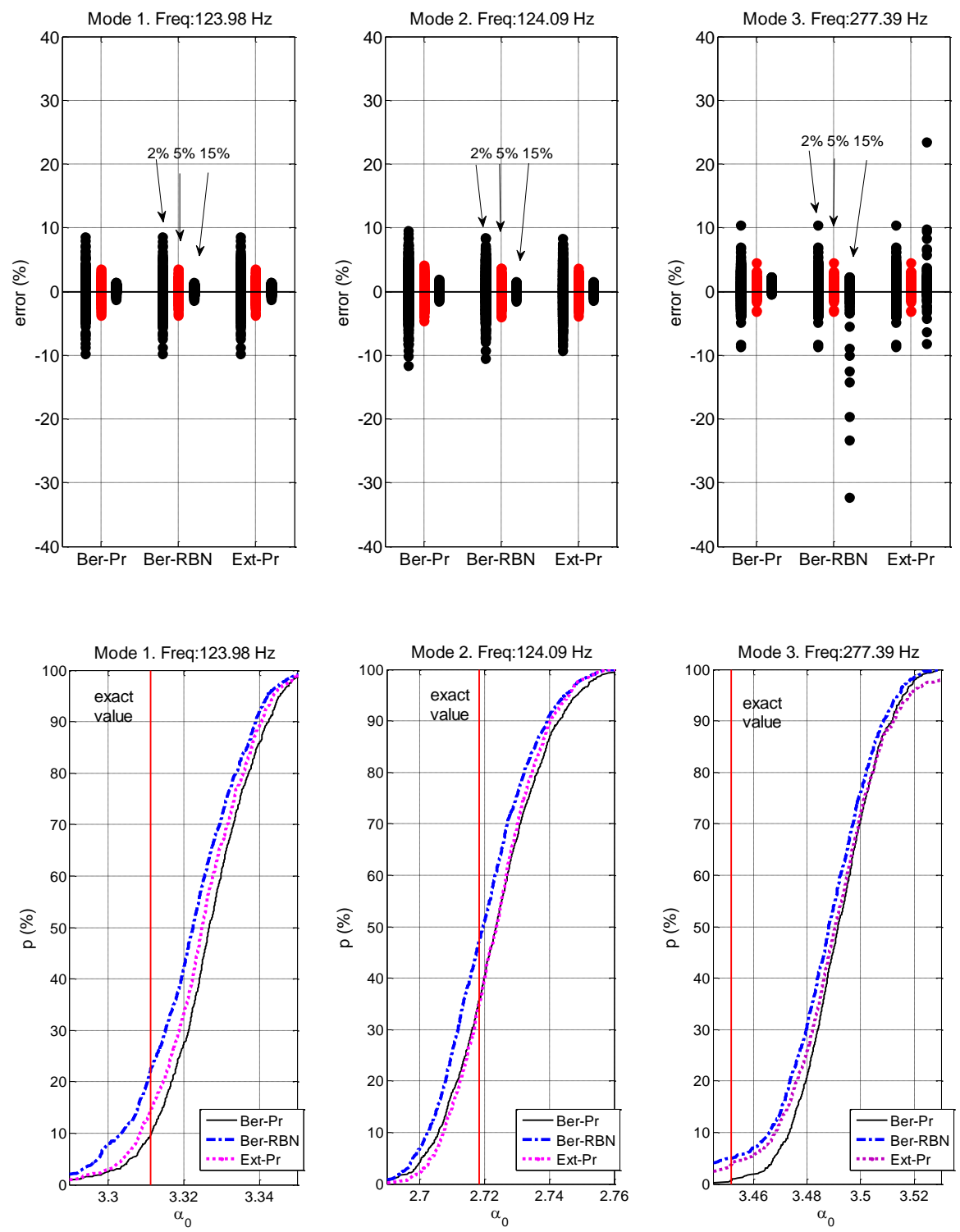

Fig. 6 Results of simulations when errors $\left(\varepsilon_{\omega}=0.1 \%\right)$ are considered in the natural frequencies (up). Statistical distribution corresponding to a mass-change of $15 \%$ (down). 

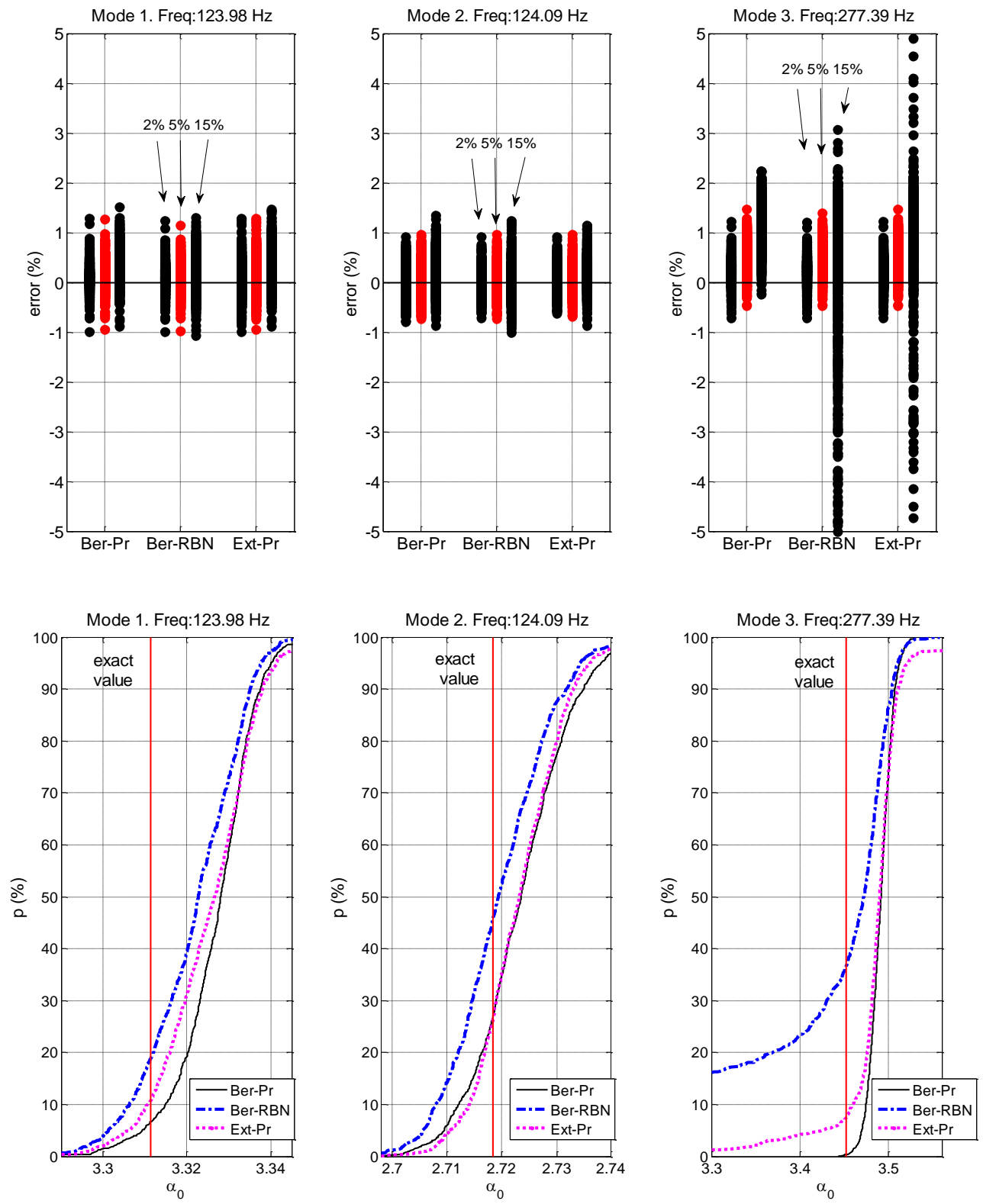

Fig. 7 Results of simulations when errors $\left(\varepsilon_{\psi}=2 \%\right)$ are considered in the mode shapes (up). Statistical distribution corresponding to a mass-change of $15 \%$ (down). 

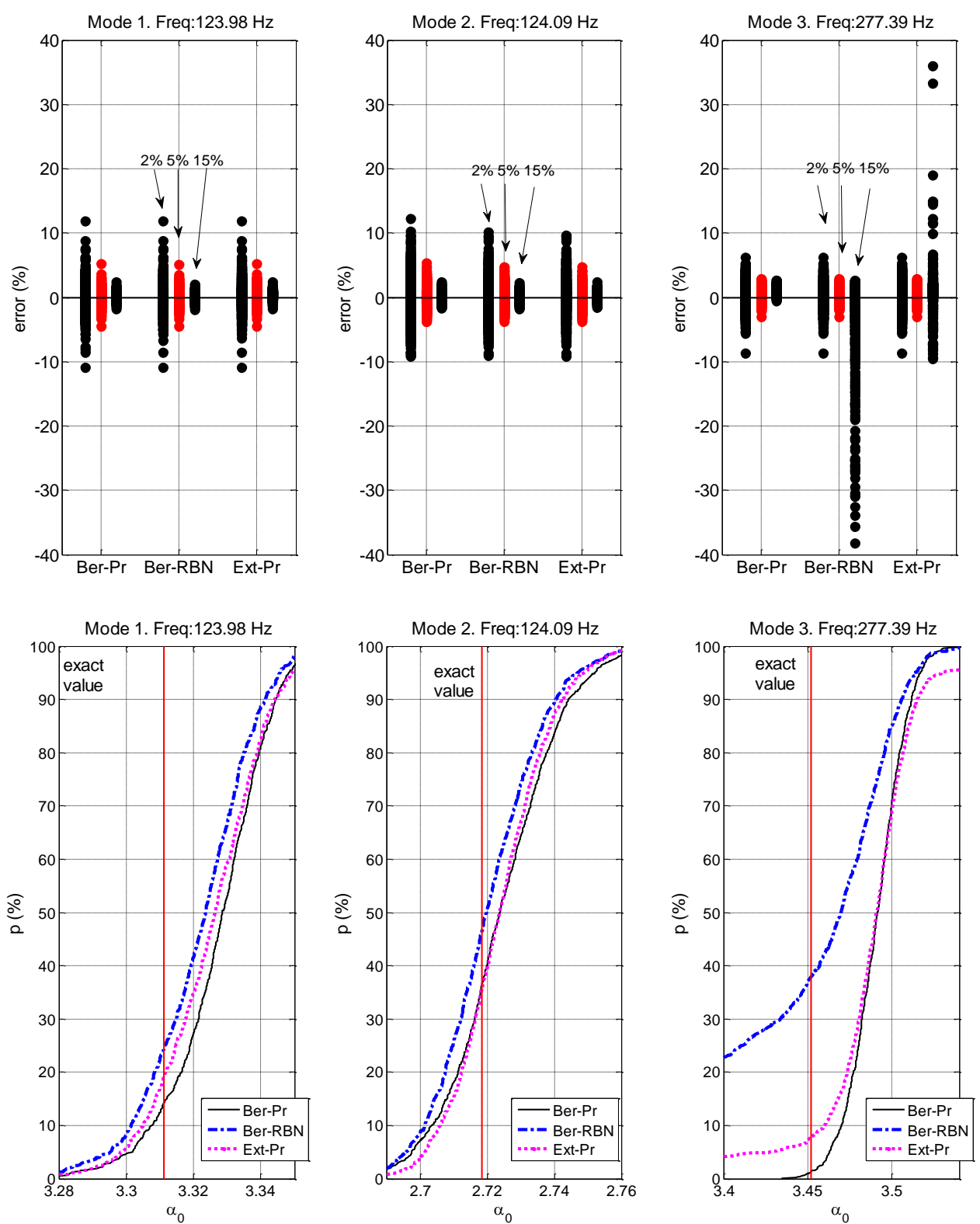

Fig. 8 Results of simulations when errors are considered in the natural frequencies $\left(\varepsilon_{\omega}=0.1 \%\right)$ and mode shapes $\left(\varepsilon_{\psi}=2 \%\right)$ (up). Statistical distribution corresponding to a mass-change of $15 \%$ (down). 
Table 1. Modal properties of the plate.

\begin{tabular}{|c|c|c|c|}
\hline Mode & $\begin{array}{c}\text { Natural } \\
\text { Frequency } \\
(\mathrm{Hz})\end{array}$ & $\begin{array}{l}\text { Scaling } \\
\text { Factor }\end{array}$ & Mode Shape \\
\hline 1 & 123.98 & 3.3113 & \\
\hline 2 & 124.09 & 2.7184 & \\
\hline 3 & 277.39 & 3.4517 & \\
\hline 4 & 329.95 & 2.8361 & \\
\hline 5 & 336.3900 & 3.6770 & \\
\hline
\end{tabular}


Table 2. Errors obtained in the scaling factors of the modified structure.

\begin{tabular}{|c|c|c|c|c|c|}
\hline \multicolumn{2}{|c|}{ Errors in } & \multirow{3}{*}{ Mode } & \multirow{2}{*}{\multicolumn{3}{|c|}{ Mass-change }} \\
\hline \multirow{2}{*}{$\begin{array}{c}\text { Natural } \\
\text { frequencies }\end{array}$} & \multirow{2}{*}{$\begin{array}{l}\text { Mode } \\
\text { shapes }\end{array}$} & & & & \\
\hline & & & $2 \%$ & $5 \%$ & $15 \%$ \\
\hline \multirow{3}{*}{ No } & \multirow{3}{*}{ No } & 1 & 10 & 10 & 20 \\
\hline & & 2 & 5 & 20 & 30 \\
\hline & & 3 & 10 & 10 & 20 \\
\hline \multirow{3}{*}{$\begin{array}{c}\text { Yes } \\
\left(\varepsilon_{\omega}=2 \%\right)\end{array}$} & \multirow{3}{*}{ No } & 1 & 20 & 20 & 22 \\
\hline & & 2 & 20 & 22 & 30 \\
\hline & & 3 & 10 & 12 & 22 \\
\hline \multirow{3}{*}{ No } & \multirow{3}{*}{$\begin{array}{c}\text { Yes } \\
\left(\varepsilon_{\psi}=2 \%\right)\end{array}$} & 1 & 20 & 20 & 22 \\
\hline & & 2 & 20 & 22 & 30 \\
\hline & & 3 & 4 & 10 & 22 \\
\hline \multirow{3}{*}{$\begin{array}{c}\text { Yes } \\
\left(\varepsilon_{\omega}=2 \%\right)\end{array}$} & \multirow{3}{*}{$\begin{array}{c}\text { Yes } \\
\left(\varepsilon_{\psi}=2 \%\right)\end{array}$} & 1 & 20 & 20 & 20 \\
\hline & & 2 & 22 & 22 & 30 \\
\hline & & 3 & 10 & 12 & 22 \\
\hline
\end{tabular}


UNMODIFIED STRUCTURE

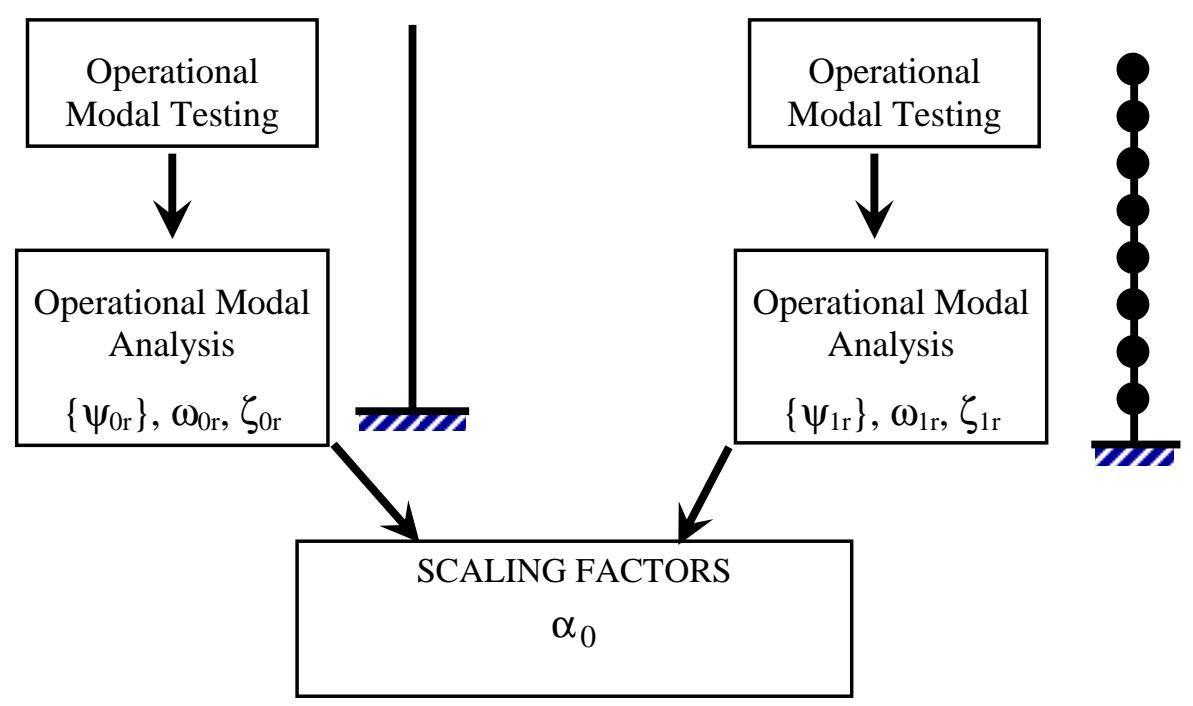

MODIFIED STRUCTURE

Operational

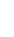

$\alpha_{0}$
Modal Testing 


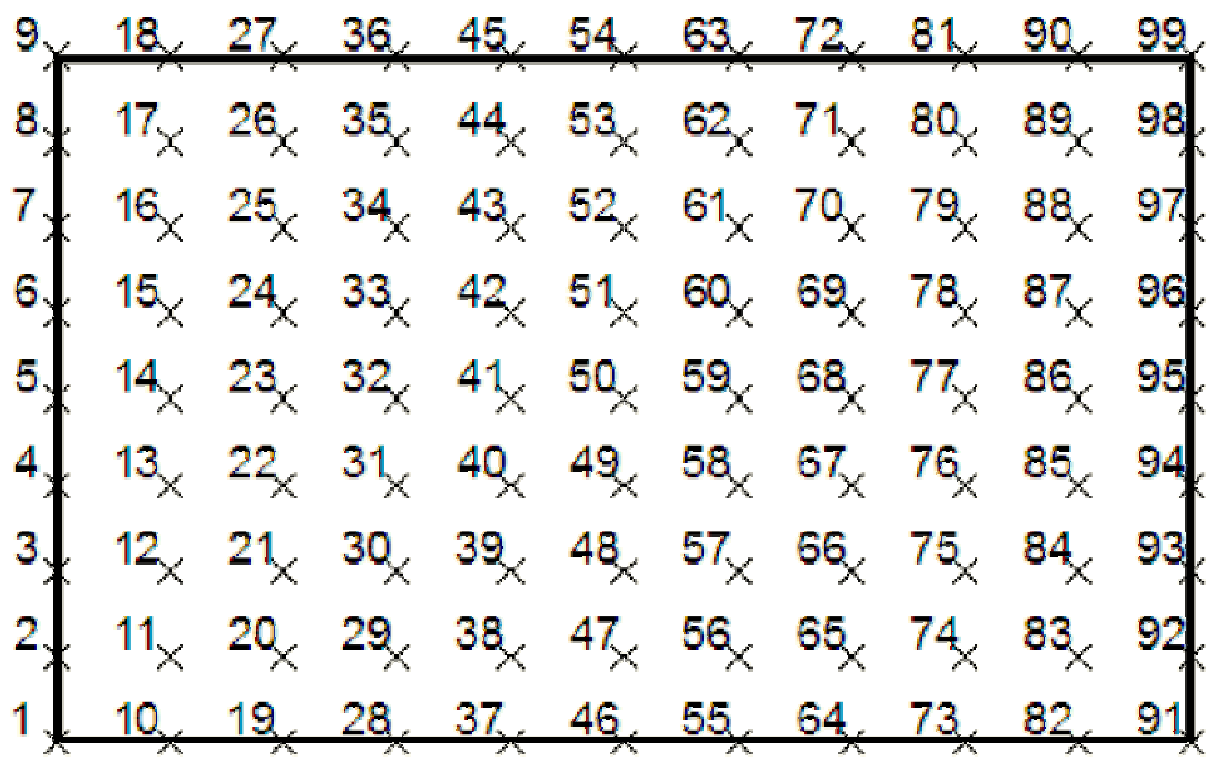




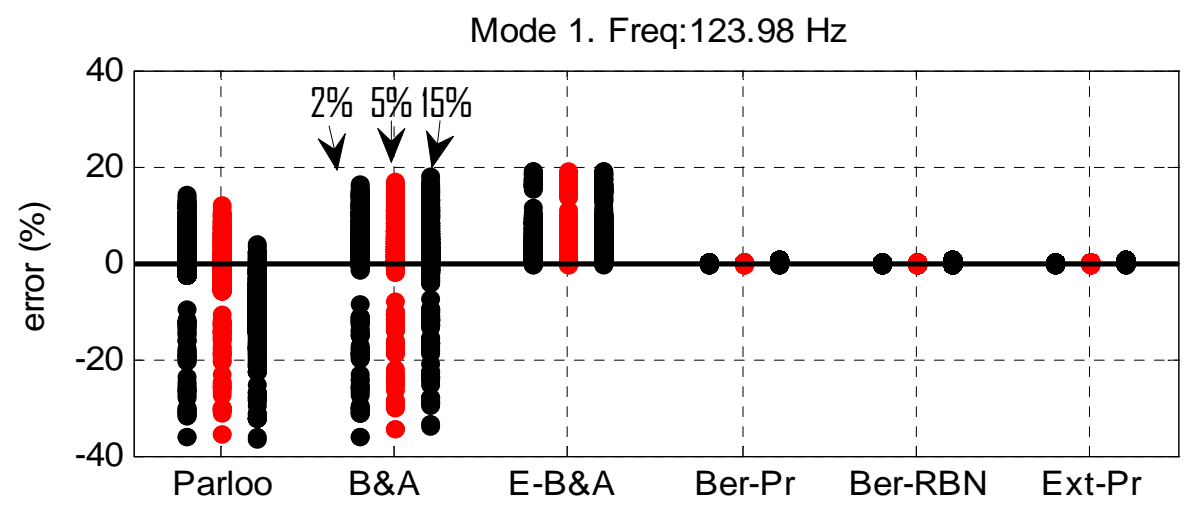

Mode 2. Freq:124.09 Hz

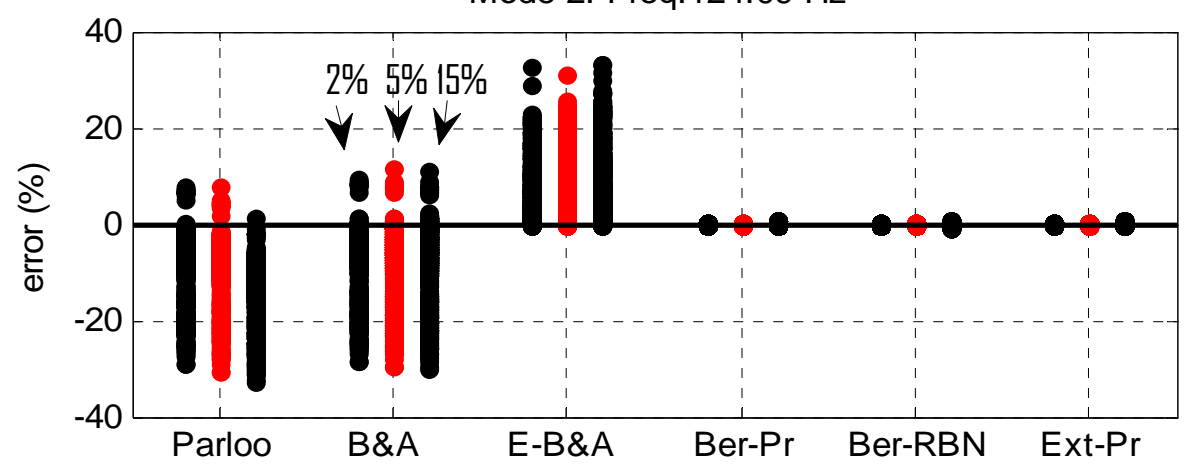

Mode 3. Freq:277.39 Hz

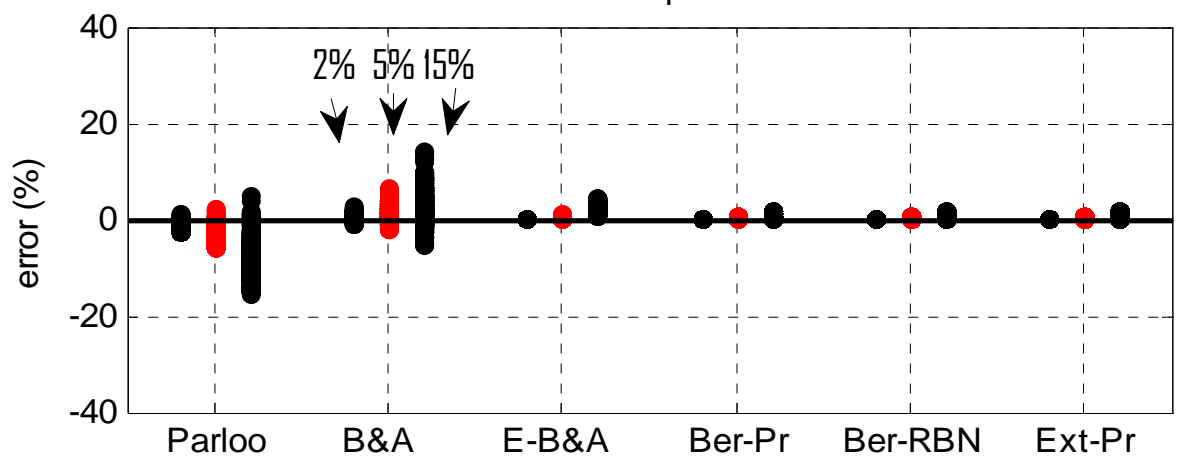



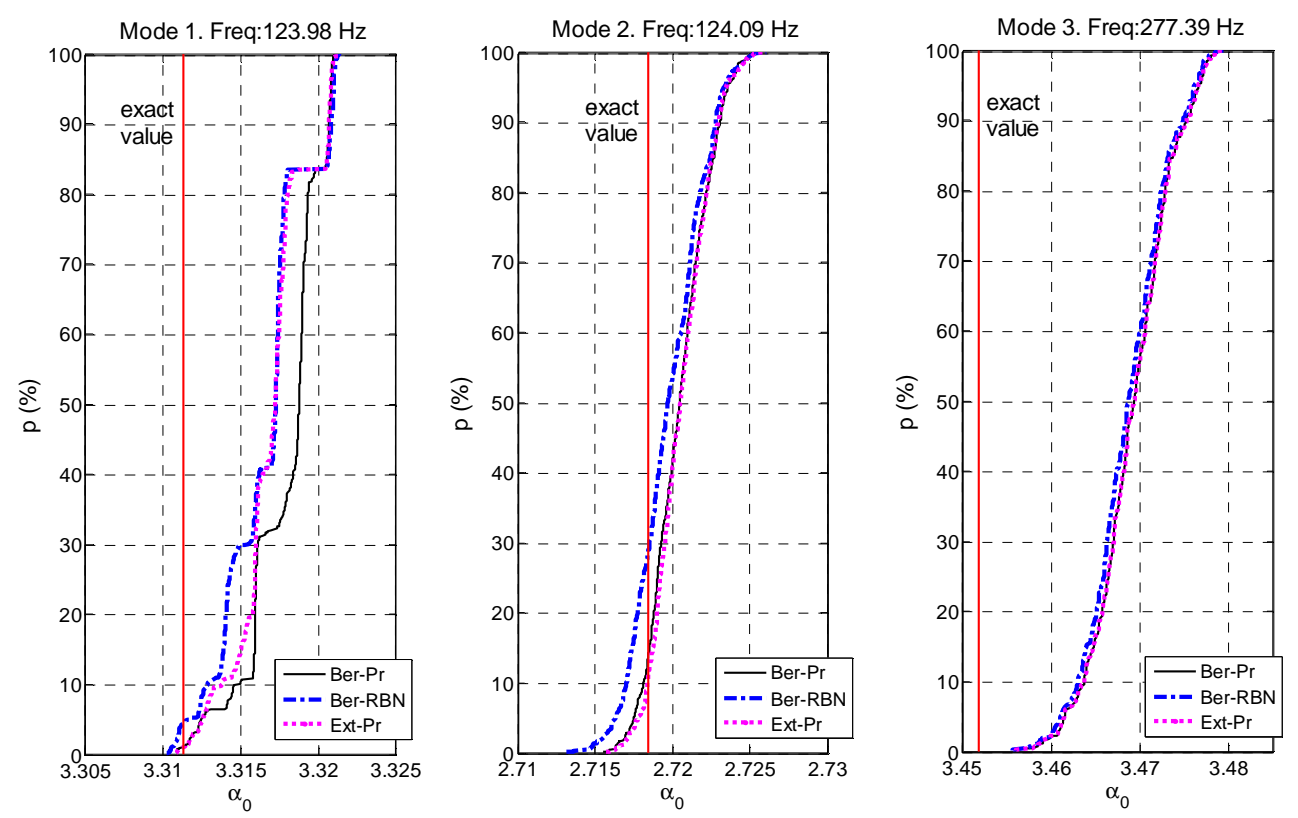

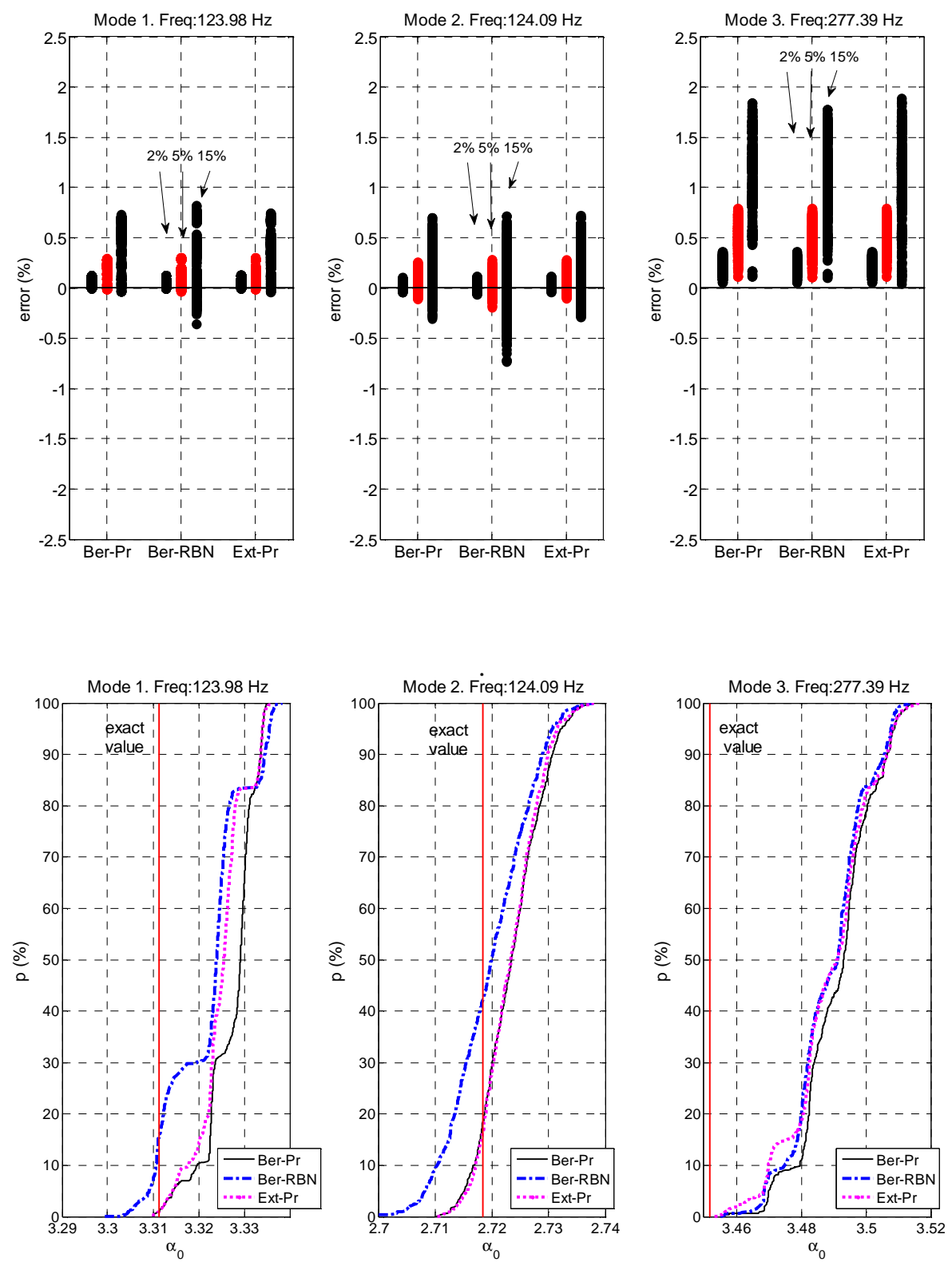

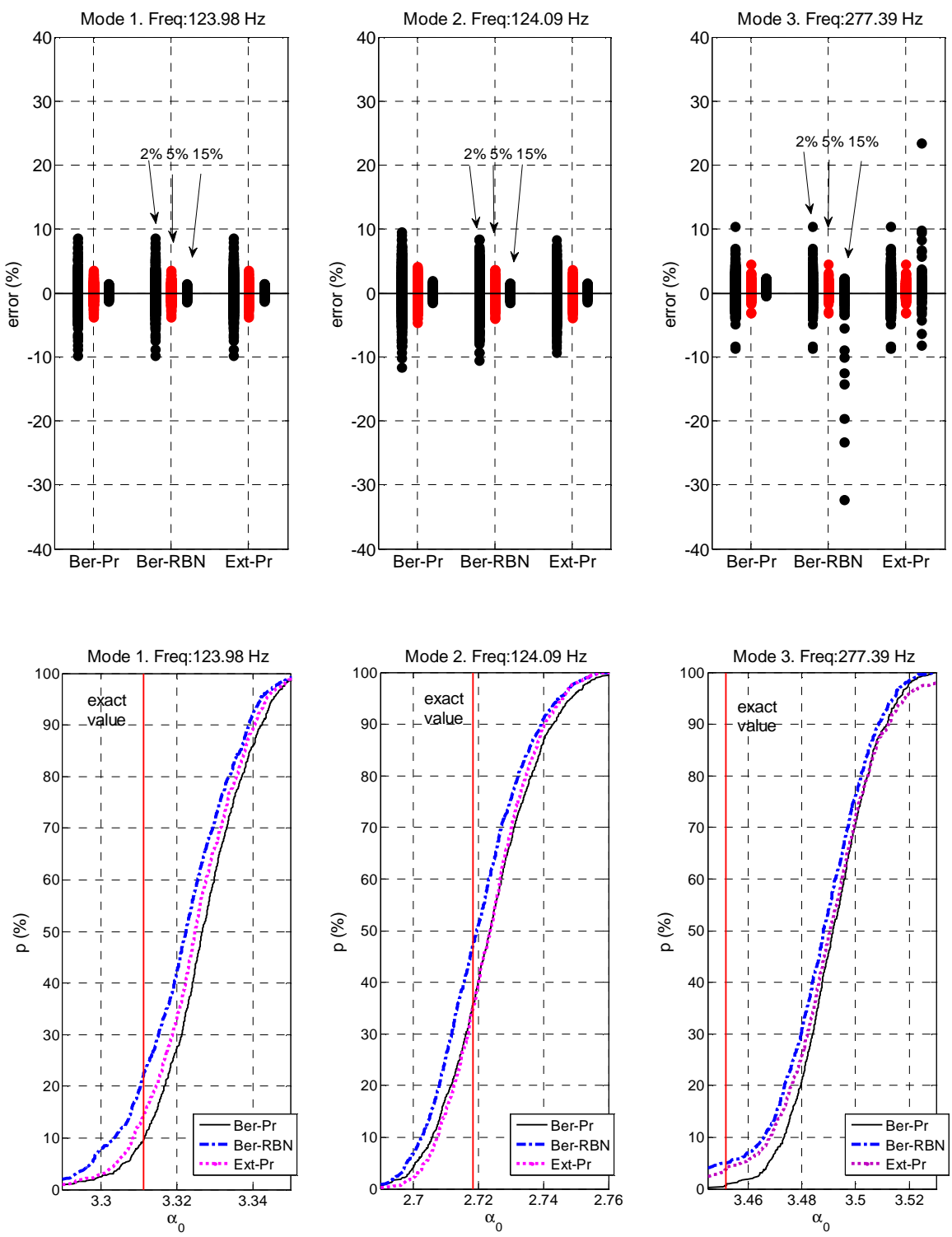

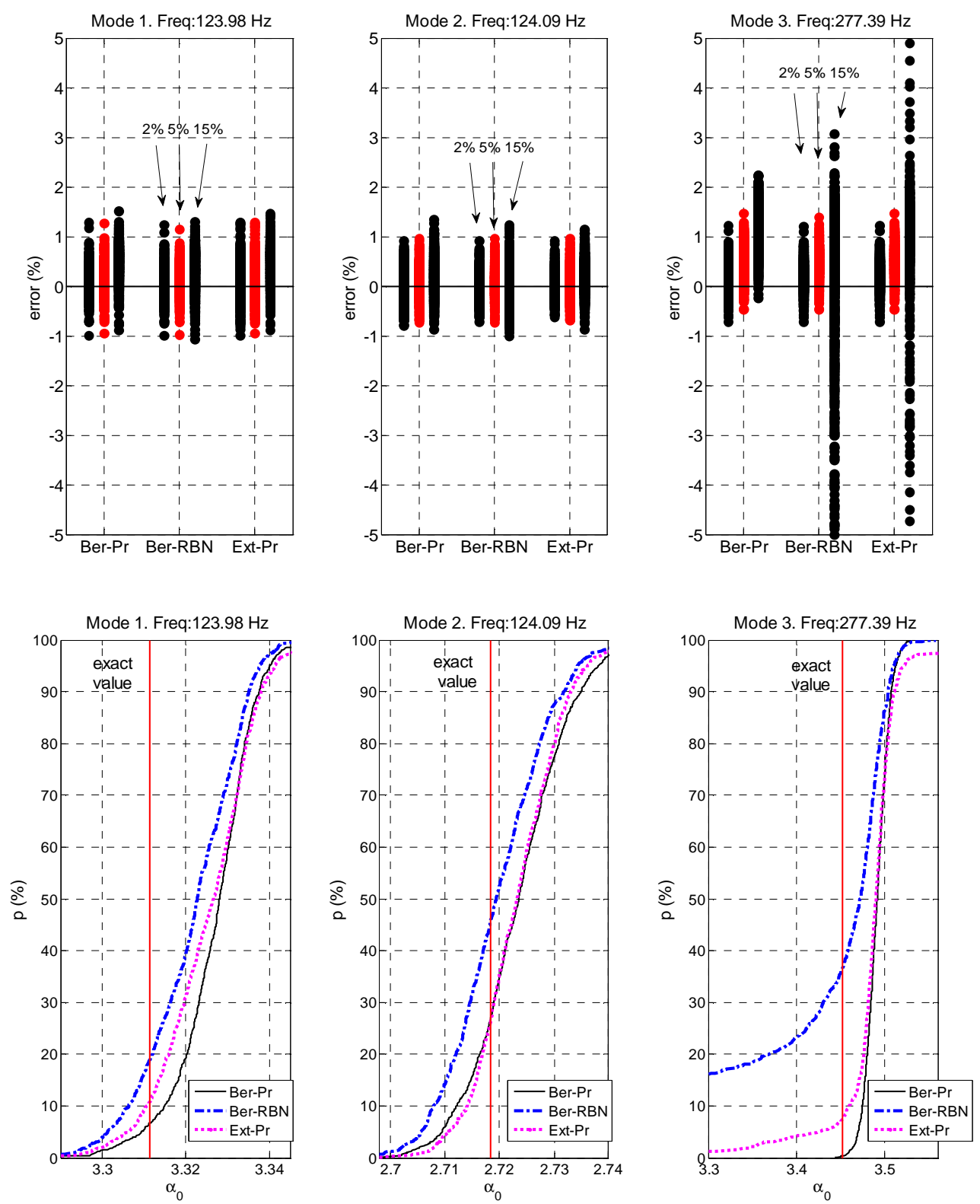

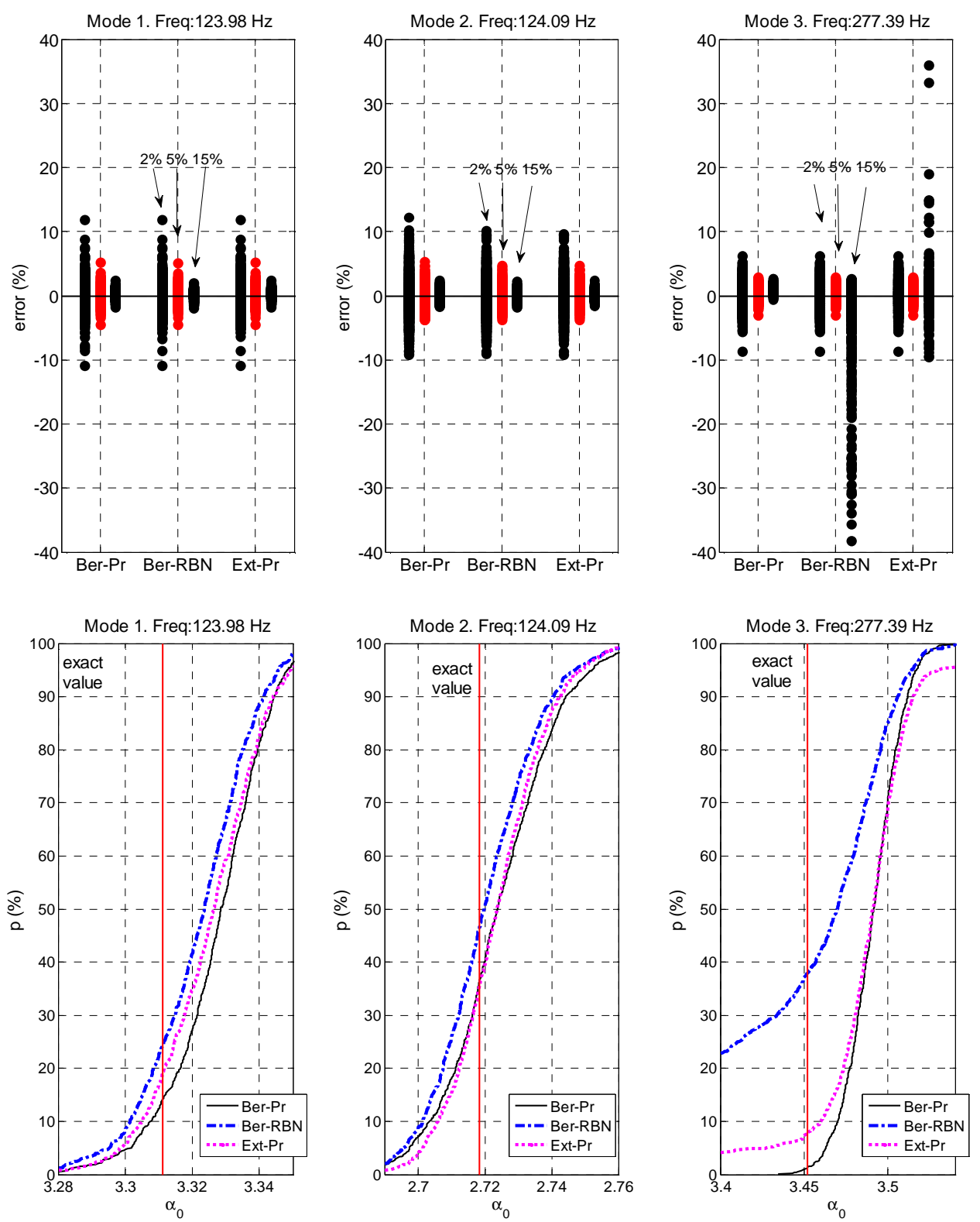


\begin{tabular}{|c|c|c|c|}
\hline Mode & $\begin{array}{c}\text { Natural } \\
\text { Frequency } \\
\text { (Hz) }\end{array}$ & $\begin{array}{c}\text { Scaling } \\
\text { Factor }\end{array}$ & Mode Shape \\
\hline 1 & 123.98 & 3.3113 & \\
\hline 2 & 124.09 & 2.7184 & \\
\hline 3 & 277.39 & 3.4517 & \\
\hline 4 & 329.95 & 2.8361 & \\
\hline 5 & 336.3900 & 3.6770 & \\
\hline
\end{tabular}




\begin{tabular}{|c|c|c|c|c|c|}
\hline \multicolumn{2}{|c|}{ Errors in } & \multirow{3}{*}{ Mode } & \multirow{2}{*}{\multicolumn{3}{|c|}{ Mass-change }} \\
\hline \multirow{2}{*}{$\begin{array}{l}\text { Natural } \\
\text { frequencies }\end{array}$} & \multirow{2}{*}{$\begin{array}{l}\text { Mode } \\
\text { shapes }\end{array}$} & & & & \\
\hline & & & $2 \%$ & $5 \%$ & $15 \%$ \\
\hline \multirow{3}{*}{ No } & \multirow{3}{*}{ No } & 1 & 10 & 10 & 20 \\
\hline & & 2 & 5 & 20 & 30 \\
\hline & & 3 & 10 & 10 & 20 \\
\hline \multirow{3}{*}{$\begin{array}{c}\text { Yes } \\
\left(\varepsilon_{\omega}=2 \%\right)\end{array}$} & \multirow{3}{*}{ No } & 1 & 20 & 20 & 22 \\
\hline & & 2 & 20 & 22 & 30 \\
\hline & & 3 & 10 & 12 & 22 \\
\hline \multirow{3}{*}{ No } & \multirow{3}{*}{$\begin{array}{c}\text { Yes } \\
\left(\varepsilon_{\psi}=2 \%\right)\end{array}$} & 1 & 20 & 20 & 22 \\
\hline & & 2 & 20 & 22 & 30 \\
\hline & & 3 & 4 & 10 & 22 \\
\hline \multirow{3}{*}{$\begin{array}{c}\text { Yes } \\
\left(\varepsilon_{\omega}=2 \%\right)\end{array}$} & \multirow{3}{*}{$\begin{array}{c}\text { Yes } \\
\left(\varepsilon_{\psi}=2 \%\right)\end{array}$} & 1 & 20 & 20 & 20 \\
\hline & & 2 & 22 & 22 & 30 \\
\hline & & 3 & 10 & 12 & 22 \\
\hline
\end{tabular}

